\title{
Nicotine Exposure during Adolescence Induces a Depression-Like State in Adulthood
}

\author{
Sergio D Iñiguez',2, Brandon L Warren ${ }^{1,2}$, Eric M Parise', Lyonna F Alcantara', Brittney Schuh', \\ Melissa L Maffeo', Zarko Manojlovic' and Carlos A Bolaños-Guzmán*,' \\ 'Program in Neuroscience, Department of Psychology, Florida State University, Tallahassee, FL, USA
}

\begin{abstract}
There is a strong link between tobacco consumption and mood disorders. It has been suggested that afflicted individuals smoke to manage mood, however, there is evidence indicating that tobacco consumption can induce negative mood. This study was designed to investigate whether nicotine exposure during adolescence influences emotionality/behavioral functioning later in life. Adolescent (postnatal days, PD 30-44) male rats were treated with twice-daily injections of nicotine $(0,0.16,0.32$, or $0.64 \mathrm{mg} / \mathrm{kg})$ for $15 \mathrm{consecutive}$ days, and their behavioral reactivity to various behavioral paradigms (the elevated plus maze (EPM), sucrose preference, locomotor activity in the open field, and forced swim test (FST) was assessed $24 \mathrm{~h}$ (short term) or I-month (long term) after exposure. Separate groups of adult rats received nicotine $(0.32 \mathrm{mg} / \mathrm{kg})$ to control for age-dependent effects. We report that nicotine exposure during adolescence - but not adulthood - leads to a depression-like state manifested in decreased sensitivity to natural reward (sucrose), and enhanced sensitivity to stress- (FST) and anxiety-eliciting situations (EPM) later in life. Our data show that behavioral dysregulation can emerge I week after drug cessation, and that a single day of nicotine exposure during adolescence can be sufficient to precipitate a depression-like state in adulthood. We further demonstrate that these deficits can be normalized by subsequent nicotine $(0.32 \mathrm{mg} / \mathrm{kg})$ or antidepressant (ie fluoxetine or bupropion; $10 \mathrm{mg} / \mathrm{kg}$ ) treatment in adulthood. These data suggest that adolescent exposure to nicotine results in a negative emotional state rendering the organism significantly more vulnerable to the adverse effects of stress. Within this context, our findings, together with others indicating that nicotine exposure during adolescence enhances risk for addiction later in life, could serve as a potential model of comorbidity.
\end{abstract}

Neuropsychopharmacology (2009) 34, I609-1624; doi:I0.1038/npp.2008.220; published online 17 December 2008

Keywords: adolescence; bupropion; depression; fluoxetine; nicotine; rats

\section{INTRODUCTION}

Nicotine dependence through tobacco smoke is the leading preventable cause of death worldwide (Ezzati and Lopez, 2003; Thompson and Fagerstrom, 2006). Although cigarette smoking has declined in recent years in the United States, this has been offset by increases in the consumption of other tobacco products (Connolly and Alpert, 2008; Delnevo et al, 2005), and $30 \%$ of those aged 12 and over report past month tobacco use (Greydanus and Patel, 2005; Johnston et al, 2006). The power of nicotine addiction is exemplified by the difficulty in quitting as most addicts wish to quit, but less than 5\% succeed (Benowitz, 1999; Hatsukami et al, 2008), and despite devastating health consequences, close to $50 \%$ of those hospitalized for tobacco-related illnesses

*Correspondence: Dr CA Bolaños-Guzmán, Program in Neuroscience, Department of Psychology, Florida State University, I 107 West Call Street, Tallahassee, FL 32306-430I, USA, Tel: + I 8506442627 ,

Fax: + | 850 645-7518, E-mail: bolanos@psy.fsu.edu

${ }^{2}$ These authors contributed equally to this work.

Received 28 July 2008; revised 13 November 2008; accepted 14 November 2008 relapse to smoking soon after leaving the hospital (Dornelas and Thompson, 2007; Thorndike et al, 2008).

The neurobiological actions of nicotine are similar to the psychomotor stimulants cocaine and amphetamine (Laviolette and van der Kooy, 2004): it interacts with neurons in the ventral tegmental area (VTA) and nucleus accumbens (NAc) - brain regions crucial for reward and addiction (Corrigall et al, 1992), enhances locomotor activity (Zubaran et al, 2000), and regulates the reinforcing properties of abused drugs (Zachariou et al, 2001). Because repeated exposure to stimulants can predispose individuals toward drug addiction (Chao and Nestler, 2004), most research has focused on delineating the mechanisms underlying nicotine dependence, treatment, and prevention (Benowitz, 2008; Picciotto, 2003).

The prevalence of nicotine dependence is significantly higher among individuals with mood disorders (Grant $e t$ al, 2004; Leonard et al, 2001), and because nicotine can alleviate negative affect, afflicted individuals may initiate smoking to regulate mood through a self-medication process (Breslau et al, 2004b; Dani and Harris, 2005; Markou et al, 1998). Conversely, there is evidence suggesting 
that cigarette smoking and level of nicotine dependence might precipitate mood-related disorders, as studies show that smokers have a greater risk of becoming depressed than nonsmokers (Breslau et al, 1998; John et al, 2004; Klungsoyr et al, 2006). Most adult smokers (80\%) started during adolescence (Lenney and Enderby, 2008; Warren et al, 2008), and adolescents who smoke daily have a $70 \%$ prevalence of psychiatric disorders (Choi et al, 1997; Kandel et al, 1997), and elevated rates of comorbidity in adulthood (Clark et al, 1998; Patton et al, 2006; Volkow, 2004).

Given the co-occurrence of nicotine use/dependence and mood disorders, that smoking is mostly initiated during adolescence, and that nicotine can induce stress and precipitate depression and anxiety (O'Loughlin et al, 2002; Parrott, 1999; Volkow, 2004), it is crucial to delineate whether nicotine exposure during adolescence results in depression-like behaviors later in life. We treated adolescent male rats with twice-daily injections of saline (VEH) or nicotine $(0.16,0.32$, and $0.64 \mathrm{mg} / \mathrm{kg}$ ) for 15 days (postnatal days (PD) 30-44). After VEH or nicotine treatment, behavioral reactivity to the elevated plus maze (EPM), forced swim test (FST), sucrose preference, and the open field was assessed $24 \mathrm{~h}$ or 1 week after the last nicotine injection, or when rats reached adulthood (PD 70+). This approach was taken because nicotine interacts with mesolimbic reward pathways that are part of the neural circuitry essential in the control of mood under normal conditions (Nestler and Carlezon, 2006).

\section{MATERIALS AND METHODS}

\section{Animals}

Preadolescent (PD 25 at day of arrival) and adult (250-275 g) male Sprague-Dawley rats were obtained from Charles River Laboratories (Raleigh, NC). Rats were habituated to the animal facility for 5 days. The age at the start and duration of nicotine exposure in adolescent rats (PD 30-44) was selected because it roughly approximates adolescence (ie age 12-18 years) in humans (Andersen and Navalta, 2004; Spear, 2000; Spear and Brake, 1983). Rats were housed two per cage in clear polypropylene boxes containing wood shavings without external objects in an animal colony maintained at $23-25^{\circ} \mathrm{C}$ on a $12 \mathrm{~h}$ light/dark cycle in which lights were on between 0700 and 1900 hours. Rats were provided with food and water ad libitum.

\section{Drugs}

(-)-Nicotine hydrogen tartrate (NIC), fluoxetine hydrochloride (FLX), and bupropion hydrochloride (BPN) were obtained from Sigma (St Louis, MO). NIC was dissolved in sterile physiological saline ( $0.9 \%$ sodium chloride; VEH), and the solution was adjusted to a pH of 7.4. FLX and BPN were dissolved in sterile distilled water. NIC and BPN were administered in a volume of $1 \mathrm{ml} / \mathrm{kg}$, whereas FLX was administered in a volume of $2 \mathrm{ml} / \mathrm{kg}$. NIC doses are expressed as the free base, whereas the doses for FLX and BPN are reported as the salt form of the drug.

\section{Drug Treatments and Experimental Design}

An initial experiment was conducted to determine the short- and long-term behavioral effects of various doses of NIC using the open-field test (OFT) and the FST. Adolescent rats received subcutaneous (s.c.) injections of VEH or NIC $(0.16,0.32$, and $0.64 \mathrm{mg} / \mathrm{kg})$ twice daily ( $4 \mathrm{~h}$ apart) for 15 consecutive days (last day: PD 44). At $24 \mathrm{~h}$ after treatment (short-term group), locomotor activity (ie distance traveled) in the open field, or behavioral reactivity to forced swimming stress, was assessed. Rats exposed to the open field were left undisturbed for 1 month (long-term group) after the test, and then exposed to the FST in adulthood $(\mathrm{PD} 70+)$. Although reliable effects in the FST were observed with both of the higher doses, we chose the $0.32 \mathrm{mg} / \mathrm{kg}$ NIC dose to further assess its influence on rats' behavioral reactivity to other emotion-eliciting stimuli, and to determine whether this dose would have similar effects in NIC-naive adult rats. We also chose this dose because it is within the range of those used in models assessing neurobiological responses to NIC in vivo (Collins et al, 2004; Matta et al, 2007; Vastola et al, 2002). Accordingly, separate groups of adolescent and adult rats $(300-320 \mathrm{~g}$ at the start of drug treatment) were exposed to NIC $(0.32 \mathrm{mg} /$ $\mathrm{kg}$ ) for 15 days and their behavioral reactivity was assessed $24 \mathrm{~h}$ or 1 month after treatment. More specifically, rats assigned to short-term group were tested in a single noninvasive behavioral paradigm (ie locomotor activity, EPM, or sucrose preference), and then left undisturbed for 1 month at which time they were tested on behavioral paradigms that they had not been exposed to earlier. Rats tested in the FST $24 \mathrm{~h}$ after NIC were not exposed to further testing. Regardless of the experimental condition, rats were not exposed to more than two behavioral paradigms, and were never tested again after FST.

For the reversal experiments using the FST, rats were treated with VEH or NIC $(0.32 \mathrm{mg} / \mathrm{kg})$ as described above and assigned to post-treatment groups receiving SAL, NIC, FLX, or BPN. Rats assigned to the NIC post-treatment group received a single NIC $(0.32 \mathrm{mg} / \mathrm{kg})$ injection $10 \mathrm{~min}$ before exposure to day 2 of the FST. Rats assigned to the FLX or BPN groups received a daily injection of FLX $(10 \mathrm{mg} / \mathrm{kg})$ or BPN $(10 \mathrm{mg} / \mathrm{kg}$ ) for 5 days (PD 70-75) before being exposed to the FST. That is, rats received their last injection of FLX or BPN $24 \mathrm{~h}$ before day 1 , or $48 \mathrm{~h}$ before day 2 of the FST. All behaviors, except for sucrose preference and locomotor activity, were recorded with a video camera located on the ceiling of separate testing rooms. In the long-term group, there was a period of at least $24-36 \mathrm{~h}$ between each behavioral test. Behavioral observations and analyses were carried out by observers with no knowledge of the treatment conditions of each rat. Experiments were conducted in compliance with the Guidelines for the Care and Use of Laboratory Animals (National Institute of Health, 1996), and approved by Florida State University Animal Care and Use Committee.

\section{Locomotor Activity}

VEH- and NIC-treated adolescent and adult rats were tested to examine the short- and long-term effects of NIC on 
locomotor activity as indexed by distance traveled $(\mathrm{cm})$ in an open-field apparatus $(63 \times 63 \times 26 \mathrm{~cm})$ for $1 \mathrm{~h}$.

\section{Elevated Plus Maze}

VEH- and NIC-treated adolescent and adult rats were tested for $5 \mathrm{~min}$ on the EPM, a behavioral model of anxiety-like behavior. The maze was made of gray plastic and consisted of two perpendicular, intersecting runways $(12 \mathrm{~cm}$ wide $\times 100 \mathrm{~cm}$ long). One runway had tall walls $(40 \mathrm{~cm}$ high) or 'closed arms,' whereas the other one had no walls or 'open arms.' The arms were connected together by a central area, and the maze was elevated $0.5 \mathrm{~m}$ from the floor. Testing was conducted between 0900 and 1300 hours under controlled light conditions ( $\sim 90 \mathrm{lux}$ ). At the beginning of the test, rats were placed in the central area, facing one of the open arms, and the cumulative time spent in the open arms was videotaped. We also assessed self-grooming in the 'closed arms' because rats engage in repetitive grooming in response to anxiogenic stimuli (Spruijt et al, 1988).

\section{Sucrose Preference}

This test consisted of a two-bottle choice paradigm in which rats are given the choice between consuming water $v s$ sucrose. This paradigm has been used extensively to assess the effects of stress-induced anhedonia (Papp et al, 1991; Sampson et al, 1992). Rats were habituated to drink water from two bottles for 5 days. Each day the water bottles were switched (left or right). At the start of the experiment (day 5) potential bottle and side preference(s) was assessed by measuring water/water intake and balancing the position of the bottles (left or right). On day 6, rats were exposed to sucrose $(0,1 \%)$ for $24 \mathrm{~h}$. The position of the sucrose bottle (left or right) was again balanced between the groups/cages. More specifically, the position of the water and sucrose bottles (left or right) was switched every $30 \mathrm{~min}$ from 1900 to 2200 hours. After the $3 \mathrm{~h}$ period, rats were left undisturbed and their overnight fluid consumption was measured the next morning (0800 hour). The preference for sucrose over water (ie sucrose intake divided by the sum of total water plus sucrose intake (sucrose/(water + sucrose)) was used as a measure for rats' sensitivity to reward. No differences in sucrose preference or liquid intake were found during the $3 \mathrm{~h}$ period, thus the water and sucrose consumption data analyzed were those taken at 1900 and 0800 hours.

\section{Forced Swim Test}

The FST is a 2-day procedure in which rats are forced to swim under conditions they cannot escape. On day 1, rats are forced to swim. Initially, they engage in escape-like behaviors but eventually adopt a posture of immobility in which they make only the movements necessary to maintain their head above water. When retested $24 \mathrm{~h}$ later, rats become immobile very quickly; however, antidepressant treatment between the forced swim exposures can significantly increase their escape-like behaviors, an effect that has been correlated with antidepressant activity in humans (Cryan et al, 2002). At the start of the experiment, rats were placed in plastic cylinders $(75 \times 30 \mathrm{~cm})$ filled to $54 \mathrm{~cm}$ depth with $25^{\circ} \mathrm{C}$ water and forced to swim for $15 \mathrm{~min}$. At the end of this period, rats were removed from the water, dried with towels, and placed in a warmed enclosure for $30 \mathrm{~min}$. All cylinders were emptied and cleaned between rats. Rats were retested for $5 \mathrm{~min}$ under identical conditions $24 \mathrm{~h}$ after the forced swim (day 2). In this study, the latency to become immobile, total immobility, swimming, immobility, and climbing counts (Carlezon et al, 2003; Detke et al, 1995) were the dependent variables. Behavioral counts were taken at 5-s intervals during the 5-min retest. Latency to immobility was defined as the time at which the rat first initiated a stationary posture that did not reflect attempts to escape from the water (Lucki, 1997). To qualify as immobility, this posture had to be clearly visible and maintained for $\geqslant 2.0 \mathrm{~s}$.

\section{Statistical Analyses}

Assignment of subjects to the various testing conditions was random. Behavioral data were analyzed using mixed-design (between and within variables) repeated analyses of variance (ANOVAs) followed by Fisher's least-significant difference post hoc test. When appropriate, additional one-way ANOVAs or Student's $t$-tests were used to determine statistical significance of preplanned comparisons. Data are expressed as the mean \pm SEM. In all cases, statistical significance was defined as $p<0.05$.

\section{RESULTS}

\section{Chronic NIC Exposure on Weight Gain in Adolescent and Adult Rats}

Figure 1a shows the effects of chronic VEH or NIC $(0.16,0.32,0.64 \mathrm{mg} / \mathrm{kg})$ treatment on weight gain in adolescent rats. Repeated-measures ANOVA (for day of injection) revealed that NIC treatment significantly influenced body weight across days (within-subject main effect: $\left.\mathrm{F}_{(14,420)}=258.03, p<0.0001\right)$ and drug-treatment (betweensubject main effect: $\left.F_{(3,420)}=50.47, p<0.001\right)$. Although body weight increased with age across all groups, NICtreated rats showed significantly lower weights when compared to controls $(p<0.05)$ as of the fourth day of treatment ( $n=8$ per group). Overall, body weight between VEH- and NIC-treated groups did not differ at the time of behavioral testing in adulthood. Data presented in the inset of Figure 1a are representative of rats treated with $0.32 \mathrm{mg} /$ $\mathrm{kg}$ NIC during adolescence, and tested for sucrose preference in adulthood. As can be seen in Figure 1b, NIC $(0.32 \mathrm{mg} / \mathrm{kg})$ or $\mathrm{VEH}$ treatment did not affect weight gain in adult rats ( $n=7$ per condition).

\section{Short- and Long-term Effects of NIC Exposure During Adolescence on Locomotor Activity}

VEH- and NIC-treated adolescent rats were placed in an open-field apparatus $24 \mathrm{~h}$ after the last injection. Figure $2 \mathrm{a}$ shows that the effects of NIC exposure varied across time (within-subject main effect: $F_{(11,396)}=141.28, p<0.0001$ ), and as a function of NIC dose (treatment main effect: $\left.\mathrm{F}_{(3,396)}=14.81, p<0.0001\right)$. In general, rats treated with the $0.32 \mathrm{mg} / \mathrm{kg}$ NIC dose had longer distance traveled for the 

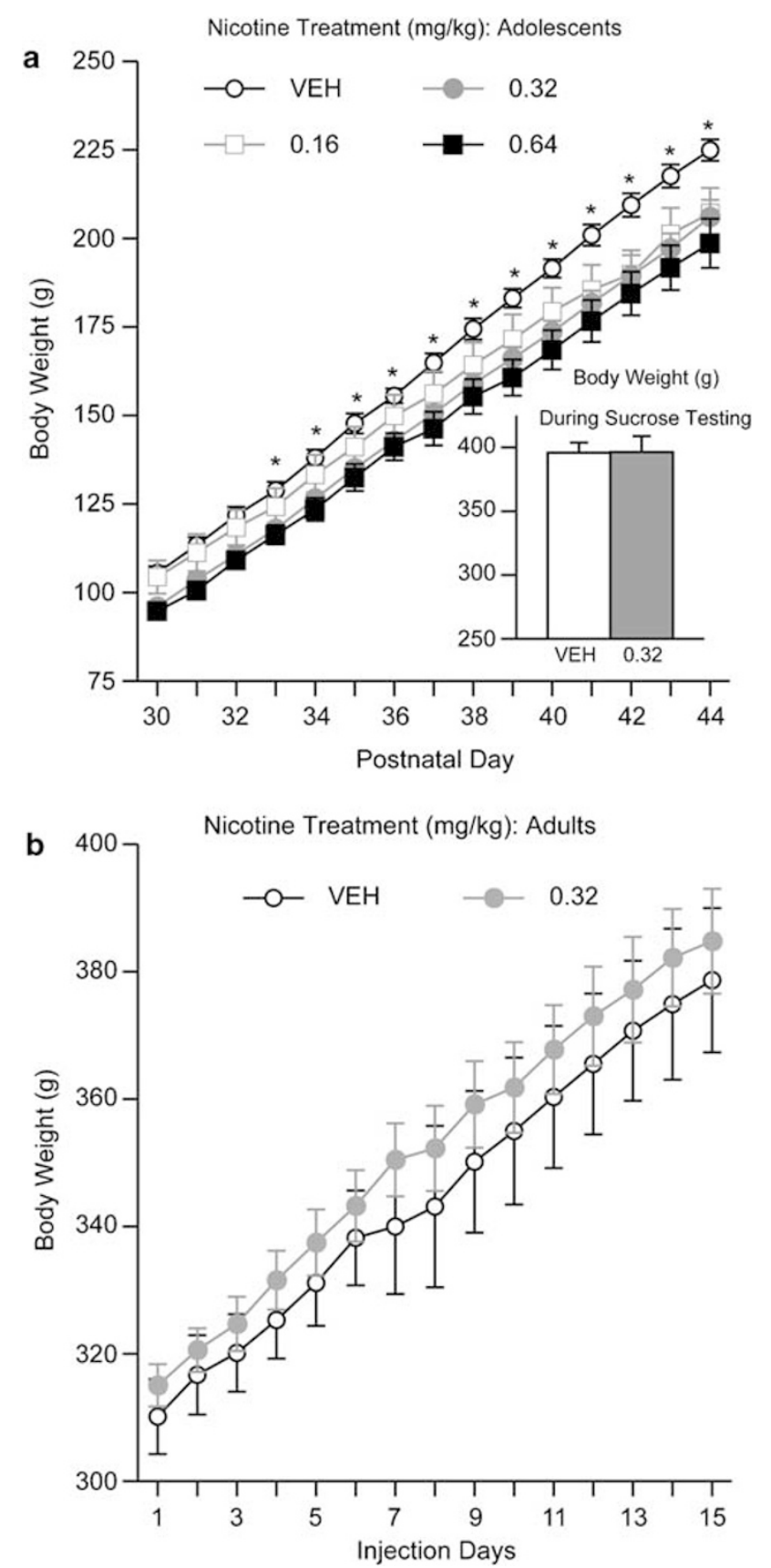

Figure I Effects of (-)-nicotine hydrogen tartrate (NIC) on weight gain (a and b). (a) Adolescents $(n=32)$ : body weight increased across days regardless of condition, and NIC treatment resulted in significantly lower weight gain when compared to control rats. *Significantly different from NIC-treated rats $(p<0.05)$. (b) Adults $(n=14)$ : no difference in body weight after NIC $(0.32 \mathrm{mg} / \mathrm{kg})$ was apparent. Data are presented average weight gain across days and drug treatment (mean \pm SEM, in gram).

first $30 \mathrm{~min}$ of the test. As can be seen in the inset of Figure $2 \mathrm{a}$, rats exposed to 0.32 NIC traveled greater distance overall (treatment main effect: $\mathrm{F}_{(3,33)}=2.88, p<0.05$ ), especially when compared to the VEH $(p<0.05)$ and the 0.16 NIC $(p<0.05)$ treatment groups $(n=9-10$ per condition).

Separate groups of VEH- and NIC-treated adolescent rats were tested in the open field when they reached adulthood
(PD 70+; Figure 2b). The effects of NIC on distance traveled varied across time (within-subject main effect: $\left.\mathrm{F}_{(11,264)}=99.45, p<0.0001\right)$, and as a function of NIC dose (treatment main effect: $\left.\mathrm{F}_{(11,264)}=7.5, p<0.0001\right)$. However, a treatment effect was only apparent at $20 \mathrm{~min}$ in the $0.64 \mathrm{mg} / \mathrm{kg}$ NIC group. The inset of Figure $2 \mathrm{~b}$ shows no differences in overall distance traveled across any of the treatment groups ( $n=6-8$ per condition).

\section{Short- and Long-term Effects of NIC Exposure on Locomotor Activity in Adult Rats}

VEH- and NIC-treated adult rats were placed in an openfield apparatus $24 \mathrm{~h}$ or 1 month after the last injection (Figure $2 \mathrm{c}$ and $\mathrm{d}$ ). Chronic exposure to $0.32 \mathrm{mg} / \mathrm{kg}$ NIC did not influence distance traveled in the open field $24 \mathrm{~h}$ (Figure 2c; $n=14$ ), or 1 month after NIC treatment (Figure 2d; $n=12$ ).

\section{Short- and Long-term Effects of NIC Exposure During Adolescence on Forced Swimming Behavior}

We used the FST to study rats' responses to stressful conditions either $24 \mathrm{~h}$ or when they reached adulthood (1 month) after the last VEH or NIC injection (Figure 3a-f). There were no significant differences in latency to immobility, or total immobility, in adolescent rats tested $24 \mathrm{~h}$ after NIC treatment on day 2 of the FST (Figure $3 \mathrm{a}$ and b). Nevertheless, NIC exposure influenced immobility $\left(\mathrm{F}_{(3,29)}=8.73 ; p<0.0001\right)$, swimming $\left(\mathrm{F}_{(3,29)}=3.29\right.$; $p<0.036)$, and climbing $\left(\mathrm{F}_{(3,29)}=11.09 ; p<0.0001\right)$ counts (Figure 3c). For instance, adolescent rats treated with 0.32 or 0.64 NIC had significantly lower levels of immobility $(p<0.05)$, and higher levels of swimming $(p<0.05)$ and climbing $(p<0.05)$ counts than VEH- or the $0.16 \mathrm{mg} / \mathrm{kg}$ NIC-treated rats ( $n=7-9$ per condition).

When assessing the long-term effects of adolescent exposure to NIC, a different behavioral profile emerged indicative of a depression-like effect (Figure 3d-f). Exposing adolescent rats to NIC resulted in significantly lower latencies to immobility in adulthood $\left(\mathrm{F}_{(3,35)}=4.23\right.$; $p<0.013$; Figure 3d). More specifically, rats treated with 0.32 or $0.64 \mathrm{mg} / \mathrm{kg}$ NIC had significantly lower latencies to immobility $(p<0.05)$ than VEH- or the $0.16 \mathrm{mg} / \mathrm{kg}$ NICtreated rats (Figure $3 \mathrm{~d}$ ). In addition, NIC-treated rats $(0.32$ and $0.64 \mathrm{mg} / \mathrm{kg}$ ) had significantly higher levels of total immobility $\left(\mathrm{F}_{(3,35)}=11.7 ; p<0.001\right)$ when compared to $\mathrm{VEH}$ and the $0.16 \mathrm{mg} / \mathrm{kg}$ dose (Figure $3 \mathrm{e}$ ); significantly higher immobility $\left(\mathrm{F}_{(3,35)}=9.36 ; p<0.0001\right.$; Figure $\left.3 \mathrm{f}\right)$, and lower swimming counts $\left(\mathrm{F}_{(3,35)}=21.15 ; p<0.0001\right)$, than $\mathrm{VEH}$ - or the $0.16 \mathrm{mg} / \mathrm{kg}$ NIC-treated rats (Figure $3 \mathrm{f} ; n=9$ per condition).

\section{Short- and Long-term Effects of NIC Exposure in Adolescent and Adult Rats on Sucrose Preference}

As can be seen in Figure 4, there were no differences in side preference or water intake across the various experimental groups. A one-way ANOVA did not yield significant differences in sucrose preference in adolescent rats when tested $24 \mathrm{~h}$ after $0.32 \mathrm{mg} / \mathrm{kg}$ NIC (Figure $4 \mathrm{a} ; \mathrm{VEH}$-treated $n=8$; NIC-treated $n=8)$. However, $t$-test revealed that 

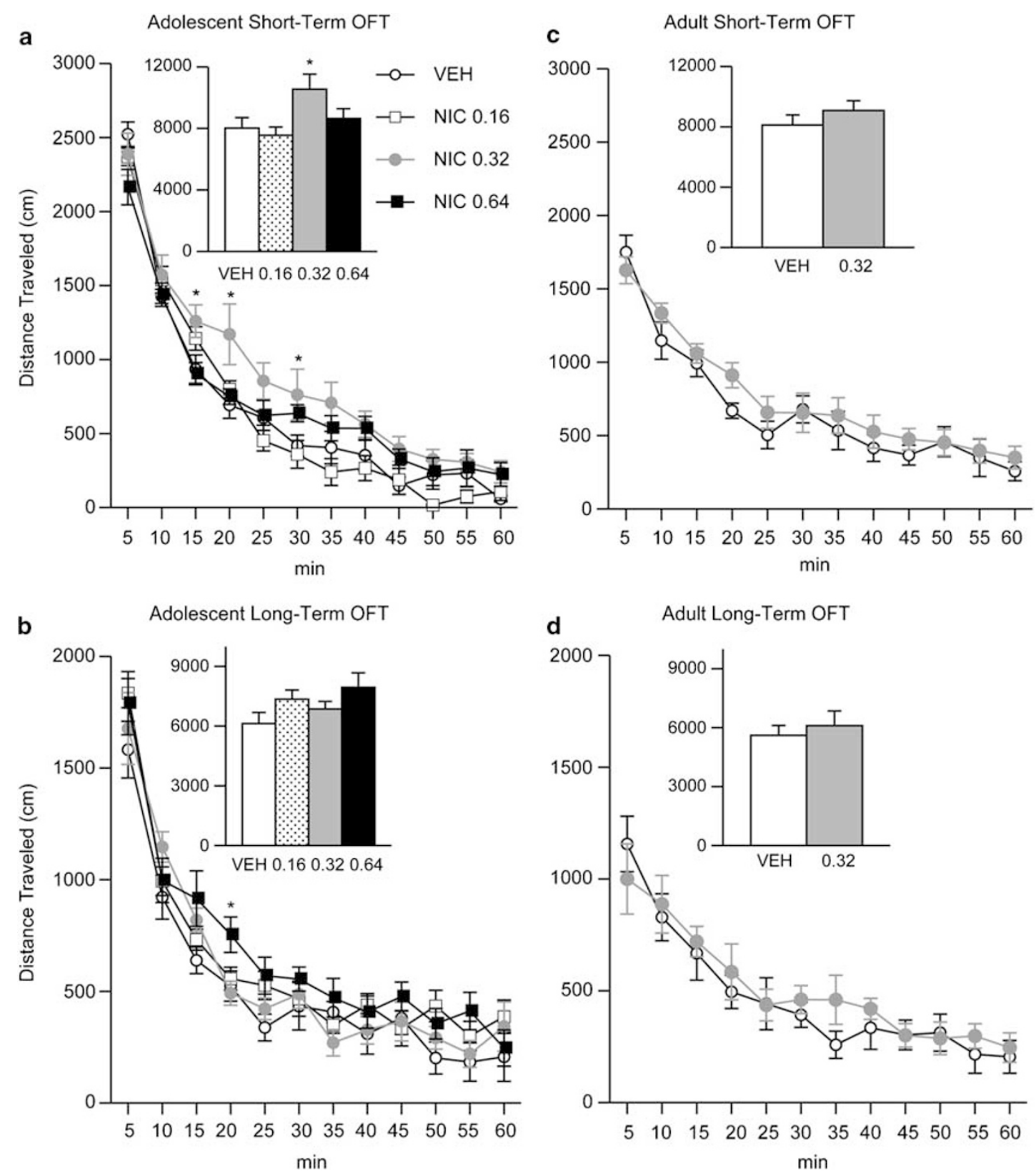

Figure 2 Effects of (-)-nicotine hydrogen tartrate (NIC) exposure on locomotor activity (a-d). (a) Short-term adolescent ( $n=37$ ): rats exposed to $0.32 \mathrm{mg} / \mathrm{kg} \mathrm{NIC}$ and tested $24 \mathrm{~h}$ after treatment had significantly higher levels of distance traveled for the first 30 min of the test (* $p<0.05$ : different from $\mathrm{VEH}$ and the $0.16,0.64 \mathrm{NIC}$ groups). (b) Long-term adolescent $(n=26)$ : no difference in locomotor activity was observed in adult rats exposed to VEH or NIC during adolescence. (c) Short-term adults $(n=14)$ : NIC $(0.32 \mathrm{mg} / \mathrm{kg})$ had no effects on distance traveled in adult rats tested $24 \mathrm{~h}$ after exposure. (d) Long-term adults $(n=12)$ : NIC $(0.32 \mathrm{mg} / \mathrm{kg})$ had no effects on distance traveled in adult rats tested 4 weeks after exposure. Data are presented as mean total distance traveled (mean \pm SEM, in $\mathrm{cm}$ ).

these rats showed a significant increase in total liquid intake $\left(t_{(14)}=5.7 ; p<0.001\right.$; Figure $4 \mathrm{~b}$, left panel) and sucrose consumption $\left(t_{(14)}=4.88 ; p<0.004\right.$; Figure $4 \mathrm{c}$, left panel) as compared to controls. A separate one-way ANOVA revealed a somewhat different pattern of results in rats treated during adolescence and tested in adulthood $\left(\mathrm{F}_{(1,18)}=12.8\right.$; $p<0.003$; Figure $4 \mathrm{a}-\mathrm{c}$, right panels). These rats exhibited a modest, yet significant decrease in sucrose preference $(p<0.05)$, and had no statistical significant changes in total liquid intake (Figure $4 \mathrm{~b}$, right panel) or total sucrose consumed (Figure 4c, right panel) when compared to VEH rats (VEH-treated $n=10$; NIC-treated $n=10$ ). As can be seen in Figure $4 \mathrm{~d}-\mathrm{f}$, there were no differences in either sucrose preference or any other parameter tested between the groups exposed to VEH or NIC in adulthood (shortterm group: VEH-treated $n=7$; NIC-treated $n=7$; longterm group: VEH-treated $n=7$; NIC-treated $n=7$ ).

\section{Short- and Long-Term Effects of NIC Exposure in Adolescent and Adult Rats on Anxiety-Like Behaviors in the Elevated Plus Maze}

We also studied the short- and long-term effects of NIC $(0.34 \mathrm{mg} / \mathrm{kg})$ exposure during adolescence on anxiety-like 
VEH
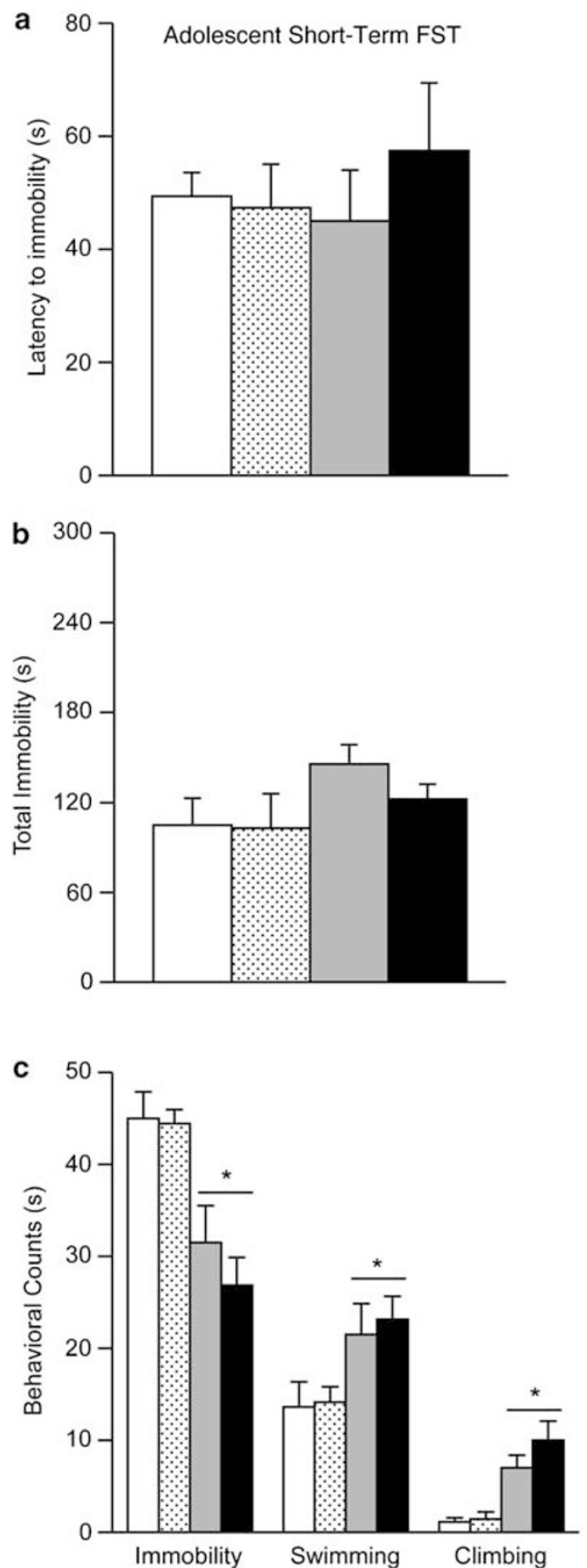

NIC 0.32

NIC 0.64
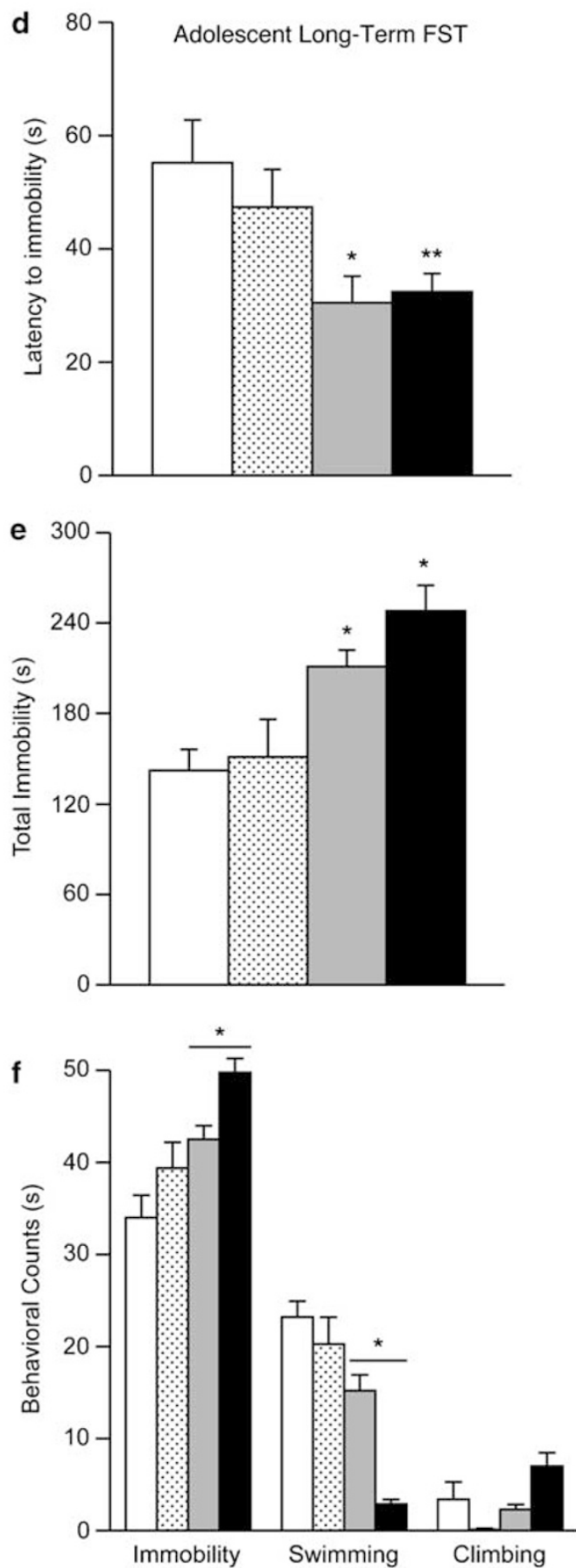

Figure 3 Effects of $(-)$-nicotine hydrogen tartrate (NIC) exposure during adolescence on forced swimming behaviors (a-f). (a) Short-term ( $n=30)$ : no significant differences in latency or (b) total immobility were found in NIC-exposed adolescent rats tested $24 \mathrm{~h}$ after exposure. (c) Rats exposed to 0.32 or $0.64 \mathrm{mg} / \mathrm{kg} \mathrm{NIC}$ had significantly lower immobility, and significantly higher swimming and climbing counts (*p<0.05: different from VEH and $0.16 \mathrm{NIC}$ ). (d) Long-term $(n=36)$ : adult rats exposed to $0.32(* p<0.05)$ or $0.64(* * p<0.05) \mathrm{mg} / \mathrm{kg} \mathrm{NIC}$ during adolescence had significantly shorter latency to immobility than the VEH and the $0.16 \mathrm{NIC}$ rats on day 2 of the forced swim test (FST). (e) These rats show higher levels of total immobility and (f) immobility counts, and lower levels of swimming and climbing ( $p<<0.05$ : different from $\mathrm{VEH}$ and $0.16 \mathrm{NIC}$ ). Data are presented as latencies to become immobile, total immobility (in seconds), swimming, immobility, and climbing counts (mean \pm SEM).

behavior using the EPM (Figure $5 \mathrm{a}-\mathrm{c} ; \mathrm{VEH}=7 ; \mathrm{NIC}=8$ ). Time spent in the open arms of the EPM did not differ between the VEH and NIC groups tested $24 \mathrm{~h}$ after the last injection. In addition, no differences in open arm entries or self-grooming were apparent (Figure $5 \mathrm{~b}$ and $\mathrm{c}$, left panel).
We then assessed the long-term effects of NIC exposure during adolescence (Figure $5 \mathrm{a}-\mathrm{c}$, right panel; $\mathrm{VEH}=9$; NIC =8). Time spent in the open arms of the EPM was influenced by NIC treatment, as rats exposed to NIC during adolescence spent significantly less time in the open arms 
$0.32 \mathrm{mg} / \mathrm{kg} \mathrm{NIC:} \mathrm{Adolescent}$

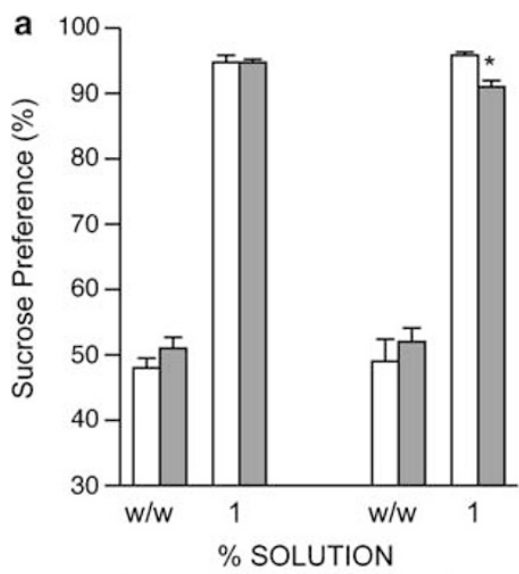

Short-term

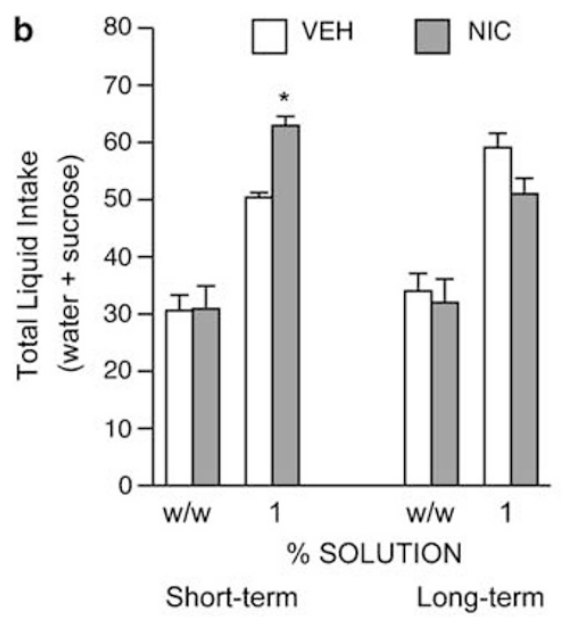

$0.32 \mathrm{mg} / \mathrm{kg}$ NIC: Adult

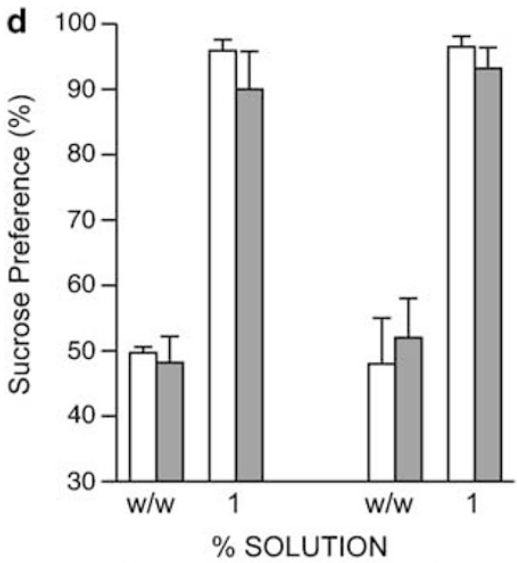

Short-term

Long-term

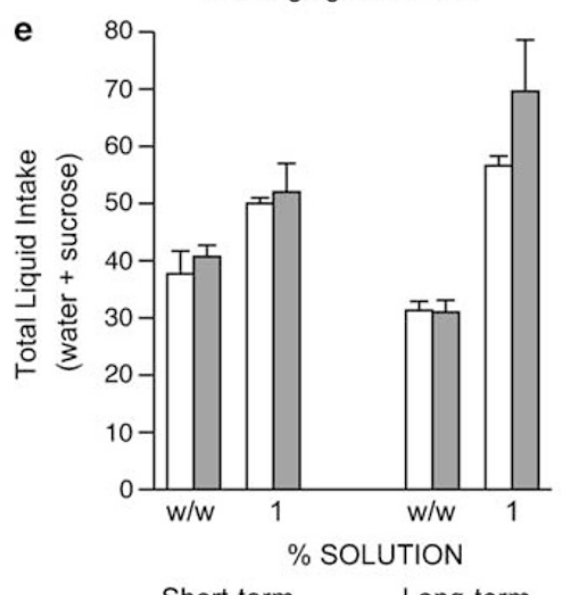

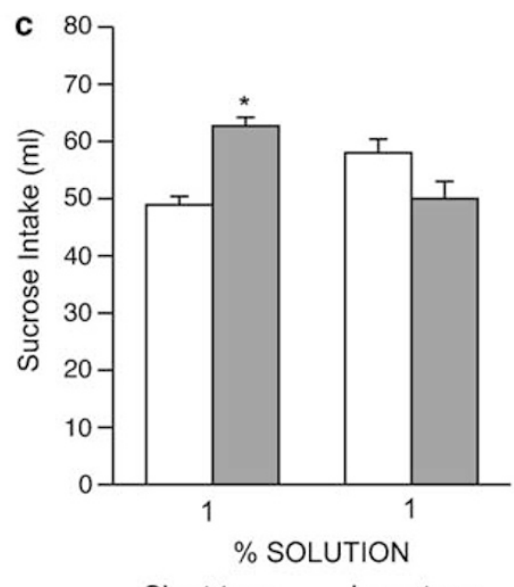

Short-term Long-term

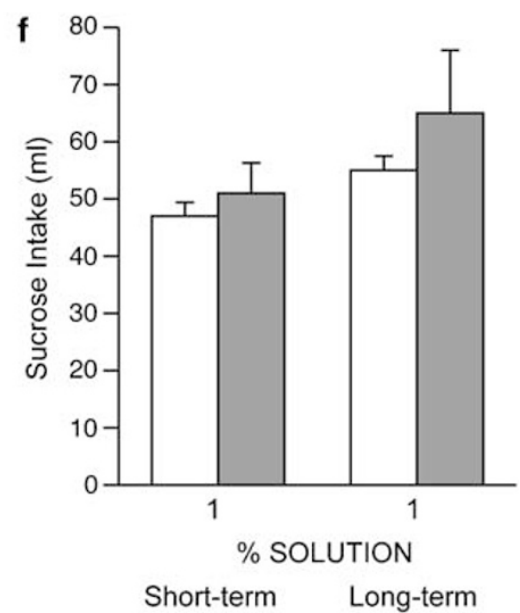

Figure 4 Effects of (-)-nicotine hydrogen tartrate (NIC) exposure in adolescent and adult rats on sucrose preference (a-f). No differences in bottle/side preference $(\mathrm{w} / \mathrm{w})$ were observed across the various groups. Short term $(n=16)$ : (a, left panel) no differences in sucrose preference detected in adolescent rats $24 \mathrm{~h}$ after NIC exposure. (b, left panel) these rats showed significantly higher levels of total liquid (sucrose + water) intake $(* p<0.05)$, and $(c$, left panel) total sucrose consumed $(* p<0.05)$ than the VEH-treated rats. Long term $(n=20)$ : (a, right panel) adolescent treatment with NIC $(0.32 \mathrm{mg} / \mathrm{kg})$ resulted in a significant decrease in sucrose preference in adulthood $(* p<0.05)$. These rats showed no differences in total liquid (sucrose + water) intake (b, right panel), or (c, right panel) in total sucrose consumed. Adult rats short term $(n=14)$ : no differences in sucrose preference detected (d-f, left panel). Adult rats longterm $(n=14)$ : no differences in sucrose preference detected $(\mathrm{d}-\mathrm{f}$, right panel). Data are presented as percent preference or total ml consumed between $\mathrm{VEH}$ - and NIC-exposed rats.

than their controls $\left(\mathrm{F}_{(1,15)}=4.67 ; p<0.04\right.$; Figure 5a, right panel). In addition, rats treated with NIC during adolescence had a significantly lower percentage entries into the open arms $\left(\mathrm{F}_{(1,15)}=62.23 ; p<0.0001\right.$; Figure $5 \mathrm{~b}$, right panel), and significantly higher levels of self-grooming in the closed arms of the EPM than controls $\left(\mathrm{F}_{(1,15)}=5.17\right.$; $p<0.038$; Figure $5 c$, right panel). NIC exposure during adulthood did not influence anxiety-related behaviors at any of the time points assessed (Figure $5 d-f$ ).

\section{Short- and Long-Term Effects of NIC Exposure in Adolescent and Adult Rats on Forced Swimming Behavior}

Figure 6a-f shows the short- and long-term effects of chronic $0.32 \mathrm{mg} / \mathrm{kg}$ NIC exposure in adolescent and adult rats. It must be noted that the short- and long-term data presented for rats treated during adolescence were taken from Figure 3 for comparison purposes. As can be seen in Figure 6 , chronic NIC did not have any short- $(n=16)$ or long-term $(n=18)$ effects in adult rats exposed to the FST.

\section{NIC Exposure During Adolescence: 1 Week After the Last NIC Injection on Forced Swimming Behavior}

Because NIC exposure had no effects on the FST $24 \mathrm{~h}$ after the last injection in adolescent rats, we assessed whether the longterm effects induced by NIC in the FST would be apparent 1 week after the last injection. Chronic NIC $(0.32 \mathrm{mg} / \mathrm{kg})$ exposure during adolescence resulted in a significant decrease in latency to immobility on day 2 of the FST $\left(\mathrm{F}_{(1,16)}=11.94\right.$; $p<0.0032$ ) 1 week after the last NIC injection (Figure 7a, $n=18$ ). In addition, these rats had significantly higher immobility counts $\left(\mathrm{F}_{(1,16)}=12 ; p<0.003\right)$, and significantly 

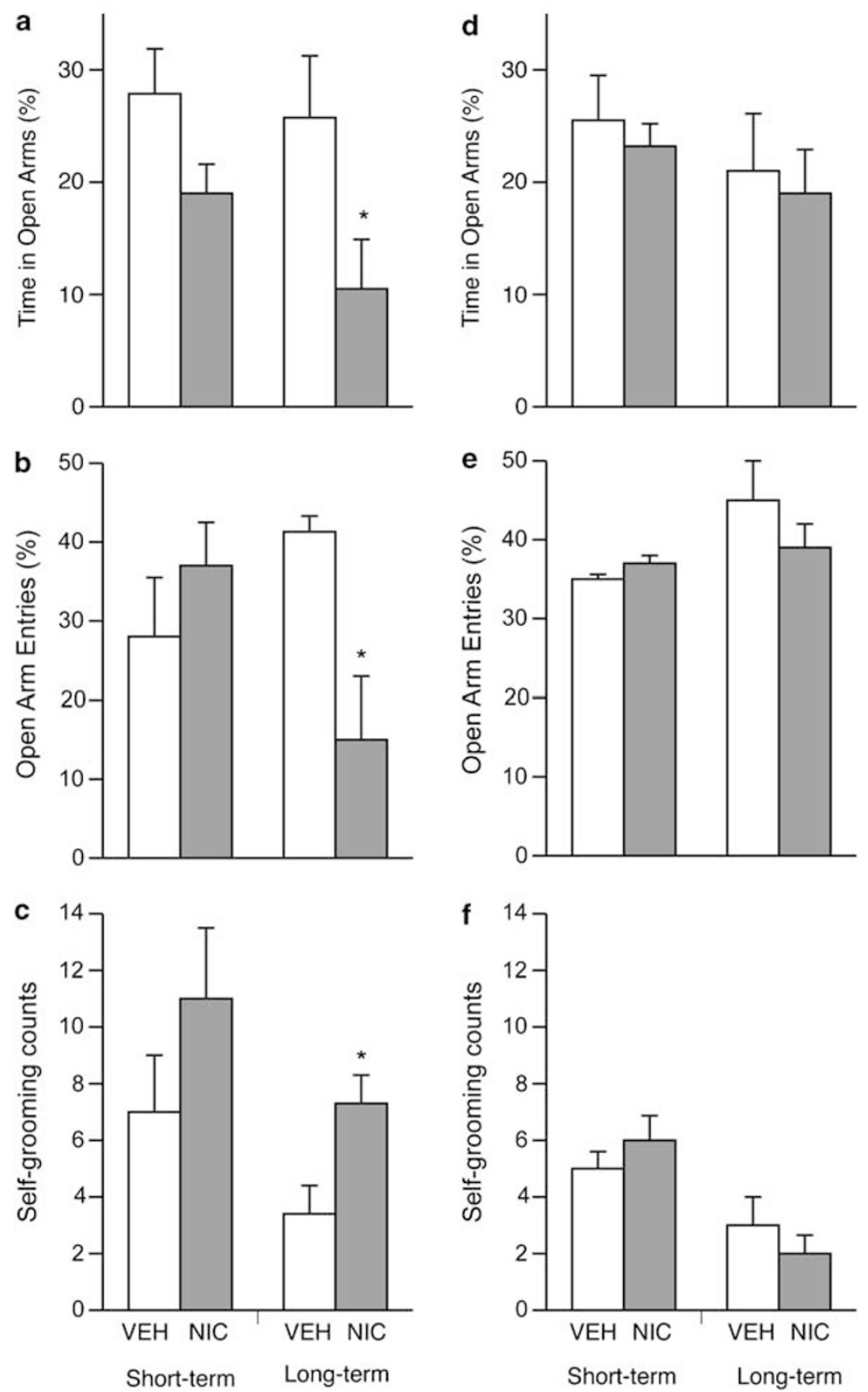

Figure 5 Effects of (-)-nicotine hydrogen tartrate (NIC) exposure in adolescent and adult rats on anxiety-like behaviors in the elevated plus maze (EPM) $(a-f)$. Short term $(n=15)$ : (a, left panel) no differences in time spent in the open arms of the EPM were observed in adolescent rats. No changes in entries into the open arms (b, left panel) or self-grooming in the closed arms (c, left panel) were detected. Long term $(n=16)$ : $(a$, right panel) adolescent rats treated with $\mathrm{NIC}$ and tested in adulthood showed a significant decrease in time spent in the open arms of the EPM when compared to controls (* $p<0.05$ ). (b, right panel) these rats demonstrated significant decreases in the percent of entries into the open arms of the EPM (*p<0.05), and (c, right panel) increased self-grooming behavior $(*<0.05)$ as compared to controls. Adult rats short term $(n=12)$ : NIC exposure had no short-term effects in adult rats $(\mathrm{d}-\mathrm{f}$, left panel). Adult rats long term $(n=\mid 4)$ : NIC had no long-term effects in adult rats ( $d-f$, right panel). Data are presented as percent time spent (mean \pm SEM) and percent entries into the open arms, and as self-grooming counts (mean \pm SEM) in the closed arms.

lower swimming counts $\left(\mathrm{F}_{(1,16)}=11.81 ; p<0.0034\right)$ than the VEH-treated rats (Figure 7c).

NIC Exposure During Adolescence: Long-Term Effects After a Single Day of NIC Exposure on Forced Swimming Behavior

It has been shown that synaptic changes are apparent in young rats after a brief exposure to NIC (Mansvelder and
McGehee, 2000). Thus, we assessed whether a single day of NIC exposure would have long-lasting behavioral effects in adolescent rats (Figure $7 \mathrm{~d}-\mathrm{f}$ ). Rats exposed to a single day of NIC (ie two injections, $0.32 \mathrm{mg} / \mathrm{kg}$ ) during adolescence (PD 30) and tested in adulthood (PD 85) did not exhibit a statistical significant decrease in latency to immobility on day 2 of the FST (Figure 7d; $n=8-10$ per condition). These NIC-treated rats had significantly higher levels of total 
immobility $\left(\mathrm{F}_{(1,16)}=5.45 ; p<0.033\right.$; Figure $\left.7 \mathrm{e}\right)$. In addition, NIC-exposed rats had significantly lower swimming counts $\left(\mathrm{F}_{(1,16)}=17.76 ; p<0.0007\right)$ than the VEH-treated rats (Figure 7f). No changes were apparent in immobility or climbing counts between groups.

\section{Long-Term Effects of NIC Exposure on the Forced Swim Test: Reversal by NIC and Antidepressant Treatment}

In this study we assessed whether NIC, FLX, or BPN could reverse the long-term behavioral deficits observed in the FST in adult rats exposed to $0.32 \mathrm{mg} / \mathrm{kg}$ NIC during adolescence (Figure 8a-c; $n=48$, ie $\mathrm{VEH} / \mathrm{SAL}=8$; $\mathrm{NIC} / \mathrm{SAL}=7 ; \mathrm{VEH} / \mathrm{NIC}=10 ; \mathrm{NIC} / \mathrm{NIC}=6 ; \mathrm{NIC} / \mathrm{FLX}=10$; $\mathrm{NIC/BPN}=7$ ). Figure $8 \mathrm{a}$ shows that behavioral responsivity on day 2 of the FST varied as a function of adolescent and adult drug treatment (pretreatment $\times$ posttreatment interaction: $\left.\mathrm{F}_{(1,42)}=10.635 ; p<0.002\right)$. More specifically, rats treated with NIC during adolescence and receiving a SAL injection on day 2 of the FST (ie NIC/SAL group) had significantly lower latencies to immobility than the VEH/SAL group $(p<0.05)$, whereas the VEH/NIC rats had significantly higher latencies to immobility than the VEH/SAL or the NIC/SAL groups $(p<0.05)$, respectively. These results replicate our original observation that NIC exposure during adolescence results in a depression-like effect in the FST, and further confirm the results of others indicating that NIC decreases immobility in the FST.

An acute injection of NIC $(0.32 \mathrm{mg} / \mathrm{kg}$, s.c. $) 10 \mathrm{~min}$ before the test reversed the effects of NIC exposure during adolescence $(p<0.05$ : as compared to the NIC/SAL and VEH/NIC groups). A single injection of FLX $(10 \mathrm{mg} / \mathrm{kg})$ or BPN $(10 \mathrm{mg} / \mathrm{kg})$ had no effect on latency to immobility (data not shown), whereas chronic (one-daily injection for 5 days) treatment to FLX or BPN reversed the effects induced by NIC exposure during adolescence in the FST $(p<0.05$ : as compared to the NIC/SAL group). The FLX dose was chosen based on previous dose-response data from our laboratory indicating that lower doses $(2.5 \mathrm{or} 5 \mathrm{mg} / \mathrm{kg}$ ) do not influence behavioral responding in the FST (Bolaños et al, 2008). The BPN dose was chosen based on previous reports demonstrating that $10 \mathrm{mg} / \mathrm{kg} \mathrm{BPN}$ is a low dose that does not enhance locomotor activity in rats previously exposed to VEH or NIC (Wilkinson and Bevins, 2007; Wilkinson et al, 2006),

$0.32 \mathrm{mg} / \mathrm{kg}$ NIC: Short-Term Effects
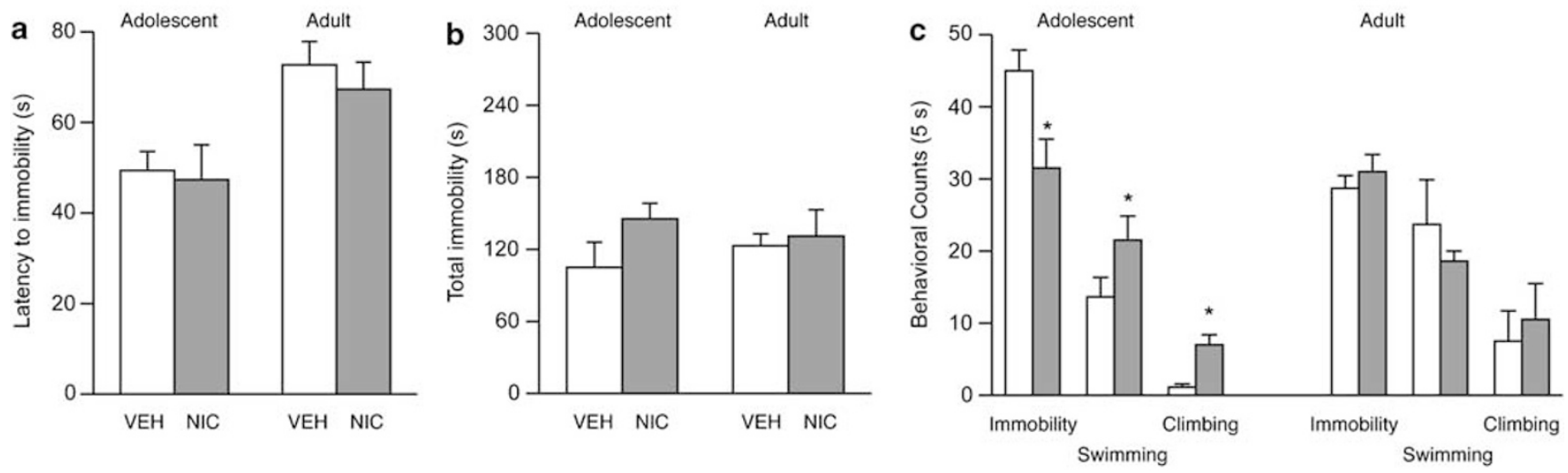

$0.32 \mathrm{mg} / \mathrm{kg}$ NIC: Long-Term Effects
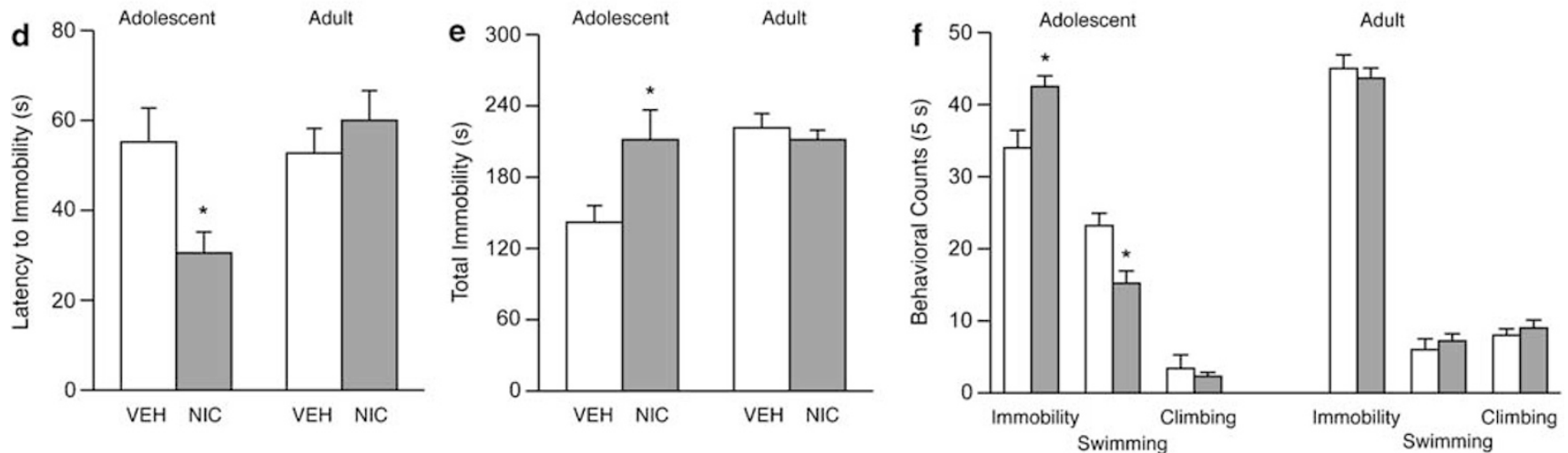

Figure 6 Effects of (-)-nicotine hydrogen tartrate ( $\mathrm{NIC}$ ) exposure in adolescent and adult rats on behavioral responsivity to forced swim stress (a-f). Note that the data for adolescent rats (short and long term) are the same as presented in Figure $3(0.32 \mathrm{mg} / \mathrm{kg})$. Short term ( $n=16)$ : (a, left panel) no significant differences in latency to immobility or ( $b$, left panel) total immobility were found in adolescent rats exposed to $0.32 \mathrm{mg} / \mathrm{kg} \mathrm{NIC}$ and tested $24 \mathrm{~h}$ after treatment. (c, left panel) these rats had significantly lower levels of immobility, and higher swimming and climbing counts (*p<0.05: different from VEH). Long term $(n=20)$ : (d, left panel) rats exposed to NIC during adolescence and tested as adults had significantly shorter latency to immobility than the $\mathrm{VEH}$ rats $(* p<0.05)$ on day 2 of the forced swim test (FST). (e, right panel) these rats also show significantly higher levels of total immobility and (f, right panel) immobility counts, whereas showing lower levels of swimming and climbing ( ${ }^{*} p<0.05$ : different from $\left.V E H\right)$. No significant differences were found in rats treated with NIC as adults and tested at the short- $(n=16)$ or long-term $(n=18)$ time points (a-f). Data are presented as latencies to become immobile, total immobility (in seconds), or swimming counts (mean \pm SEM). 

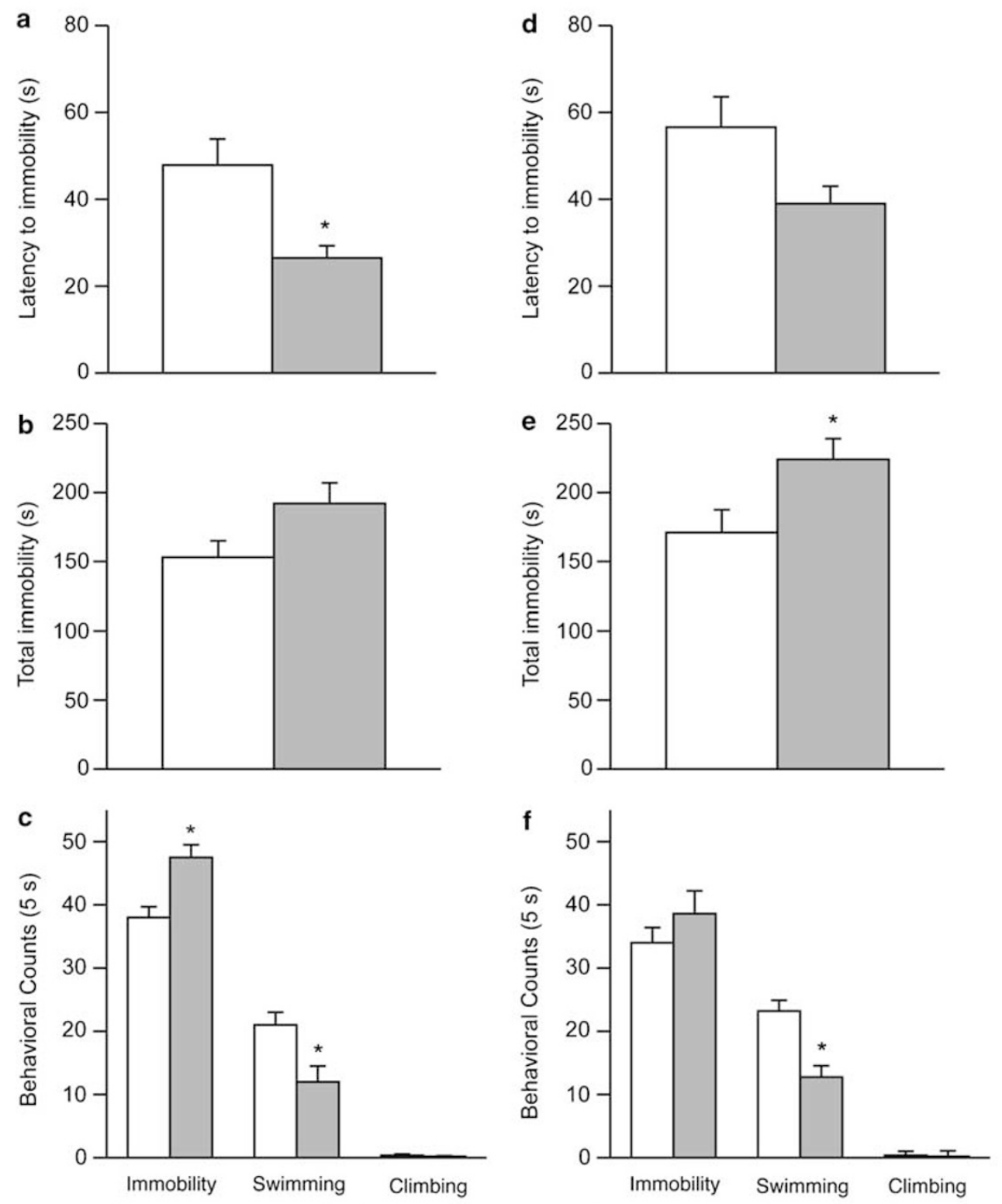

Adolescent: 1 week after last injection

Adolescent: Long-Term: 1 day NIC Exposure

Figure 7 Effects of (-)-nicotine hydrogen tartrate (NIC) exposure in adolescent rats: I week after chronic exposure (a-c), and I month after a single day of exposure $(\mathrm{d}-\mathrm{f})$ on behavioral responsivity in the forced swim test (FST). After I week $(n=18)$ : (a) NIC resulted in a significant decrease in latency to immobility of day 2 of the FST (*p $<0.05$ : different from VEH). (c) These rats show significantly higher immobility counts $(* p<0.05)$ and lower swimming counts $(* p<0.05)$ when compared to controls. I month after a single day of NIC, exposure $(n=18)$ : $(d)$ these rats show no statistical significant changes in latency to immobility, (e) but demonstrate significantly higher levels of total immobility $(* p<0.05)$, and ( $f$ ) lower swimming counts (*p<0.05) when compared to controls. Data are presented as latencies to become immobile, total immobility (in seconds), or swimming counts (mean \pm SEM).

thus avoiding potential generalized motor activity from influencing the results from the FST. A pattern consistent with the various treatments was observed when assessing total immobility (Figure $8 \mathrm{~b}$ ), as this behavior was also influenced by adolescent and adult treatment (pretreatment $\times$ posttreatment interaction: $\mathrm{F}_{(1,42)}=8.79$; $p<0.005)$. For instance, rats in the NIC/SAL group had significantly higher total immobility than the VEH/SAL $(p<0.05), \quad \mathrm{VEH} / \mathrm{NIC} \quad(p<0.05), \quad \mathrm{NIC} / \mathrm{NIC} \quad(p<0.05)$, NIC/FLX $(p<0.05)$, or the NIC/BPN $(p<0.05)$ groups, respectively. NIC exposure also influenced immobility, swimming, and climbing $\left(\mathrm{F}_{(1,42)}=10.95 ; p<0.002\right)$ counts (Figure 8c). More specifically, the NIC/SAL group had significantly higher levels of immobility $(p<0.05)$, and lower levels of swimming $(p<0.05)$ and climbing $(p<0.05)$ counts, whereas the VEH/NIC, NIC/NIC, NIC/FLX, and NIC/BPN had lower levels of immobility, and higher levels of swimming counts, respectively $(p<0.05)$. Higher levels of climbing were observed in all groups as compared to the NIC/SAL condition $(p<0.05)$. 

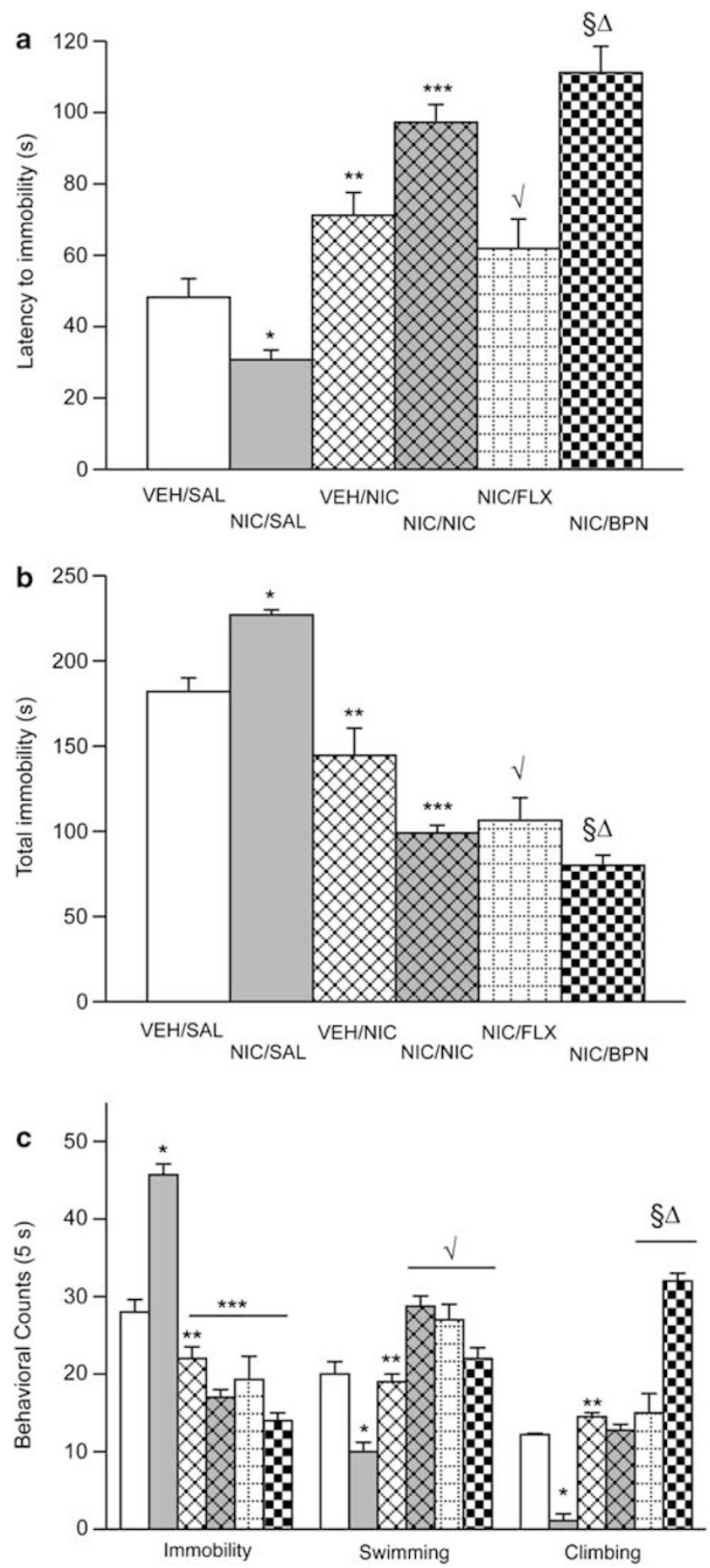

Figure 8 (-)-Nicotine hydrogen tartrate (NIC), FLX, and BPN reverse NIC-induced behavioral deficits on behavioral responsivity in the forced swim test (FST) (a-c). (a) NIC significantly decreased latency to immobility $(* p<0.05$ vs $\mathrm{VEH} / \mathrm{SAL})$. NIC $(* * * p<0.05)$ and BPN $\left({ }_{p} p<0.05\right)$ significantly increased latency to immobility when compared to the VEH/SAL and NIC/SAL groups (** $p<0.05$ vs NIC/SAL; $\sqrt{ } p<0.05$ vs NIC/SAL; ${ }^{\$} \Delta_{p}<0.05$ vs $\mathrm{VEH} / \mathrm{NIC}$ and $\mathrm{NIC/FLX).} \mathrm{(b)} \mathrm{Complementary} \mathrm{pattern} \mathrm{of} \mathrm{results} \mathrm{as}$ measured by total immobility, as well as (c) immobility $(* * p<0.05$ vs NICl SAL; ${ }^{*} * * * 0.05$ vs NIC/SAL), swimming (* $p<0.05$ vs VEH/SAL; *** $<0.05$ vs NIC/NIC and NIC/FLX; $\sqrt{ }_{p}<0.05$ vs NIC/SAL), and climbing counts (* $p<0.05$ vs VEH/SAL; ${ }^{* *} p<0.05$ vs NIC/SAL; ${ }^{\circledR} p<0.05$ vs all other conditions; $n=48$ ). Data are presented as latencies to become immobile, total immobility (in seconds), or swimming counts (mean \pm SEM).

\section{Discussion}

Given the relationship between nicotine dependence and mood disorders and that smoking often begins in adolescence, this study assessed the short- and long-lasting effects of nicotine exposure on behavioral reactivity to various emotion-eliciting stimuli in male rats. Our results demonstrate that exposure to nicotine during adolescence - but not during adulthood-leads to a depression-like state manifested in decreased sensitivity to natural reward, and enhanced sensitivity to stress- and anxiety-eliciting situations later in life. Our data show that behavioral dysregulation can emerge after 1 week of nicotine cessation, and that a single day of nicotine exposure during adolescence can be sufficient to precipitate a depressionlike state in adulthood. Furthermore, we demonstrate that these nicotine-induced deficits can be rescued by subsequent nicotine or antidepressant treatment in adulthood. Together, these data suggest that nicotine exposure during adolescence results in a negative emotional state characterized by anhedonia (an inability to experience naturally rewarding and exciting stimuli), and heightened sensitivity to the adverse effects of stress.

Exposure to nicotine during adolescence resulted in significant decreases in rats' normal sensitivity to the rewarding properties of sucrose (a natural reward) in adulthood. Deficits in sucrose preference were not present in adolescents tested $24 \mathrm{~h}$ following nicotine, nor in rats exposed as adults. Although nicotine significantly decreased adolescents' bodyweight during treatment and could have influenced sucrose consumption, this is not likely the case because bodyweight between the groups did not differ when tested in adulthood (Figure 1a, inset). In addition, if bodyweight had influenced consumption, this would have resulted in decreased sucrose preference in the short-term adolescent group because their bodyweight was significantly lower than controls. Thus, the decrease in sucrose preference is likely due to nicotine's ability to alter responsiveness to the rewarding effects of the solution, because the overall liquid intake during testing did not differ between the groups. Brain reward pathways, such as the NAc and its dopaminergic input from the VTA, are crucial in regulating responses to both natural and drug rewards (Kelley and Berridge, 2002; Koob and Le Moal, 2008). Exposure to sweet solutions activates this system increasing dopamine in the NAc, whereas disruptions in the functioning of these pathways decrease preference for sucrose and other reward-related stimuli (Hajnal and Norgren, 2001; Kelley and Berridge, 2002; Shimura et al, 2002). These results are consistent with others indicating that exposure to nicotine, as well as other psychostimulants such as methylphenidate early in life, leads to long-lasting neural alterations resulting in decreased interest in natural rewards (ie anhedonia) in adulthood (Bolaños et al, 2003, 2008; Franke et al, 2008; Mague et al, 2005). It must be noted, however, that the effect size of nicotine on sucrose preference, though statistically significant, is small, and that nicotine did not influence total sucrose intake (Figure 4c, right panel). In addition, others have not detected differences in sucrose preference after adolescent exposure to nicotine (Slawecki and Ehlers, 2002). In the previous study, the authors administered nicotine $(7.0 \mathrm{mg} / \mathrm{kg}$ per 
day) through transdermal patches for a relatively short period (5 days), and tested rats on a $2 \%$ sucrose solution, whereas in this study we used a longer treatment regimen (15 days) that included twice-daily injections of $0.32 \mathrm{mg} / \mathrm{kg}$ nicotine, and tested with a $1 \%$ sucrose concentration. In addition, we exposed rats between PD 30 and 44, whereas in the previous study rats were exposed to nicotine between PD 35 and 40. Thus, it is conceivable that differences in treatment duration and drug dosage, as well as sucrose concentration, may account for the discrepancies between the studies. Alternatively, other physiological factors such as changes in metabolism, taste sensation, and kidney function induced by nicotine exposure during adolescence as potential mediators influencing sucrose consumption cannot be ruled out.

Our findings also indicate that early life nicotine enhances rats' sensitivity to aversive situations later in adulthood. More specifically, adult rats exposed to nicotine during adolescence exhibited enhanced reactivity to anxiogenic stimuli, as they spend significantly less time in the 'open arms' of the EPM, and more time engaged in self-grooming behavior, a well-known behavioral response to anxietyeliciting situations (Spruijt et al, 1988). In addition, there were no differences in reactivity of adult rats exposed to the same regimen of nicotine exposure and testing in the EPM. These results are supported by demonstrations that nicotine exposure before adulthood results in higher indices of anxiety-like behaviors later in life (Huang et al, 2007; Slawecki et al, 2003, 2005). Under the appropriate conditions, behavioral reactivity in the OFT can also be used as an index of increased anxiety (Britton and Britton, 1981), thus it must be noted that the behavioral performance observed in the OFT under our experimental conditions do not compliment our findings of increased anxiety-like behaviors as measured in the EPM. Further studies with the FST revealed that adolescent nicotine exposure decreased latency to immobility and other escape-like behaviors, while increasing total immobility in adulthood, effects opposite to that of antidepressant treatments (Cryan et al, 2002; Lucki, 1997; Porsolt et al, 1977). These effects are not due to nicotine-induced deficits in motor activity because rats treated with nicotine $(0.32 \mathrm{mg} / \mathrm{kg})$ show no difference in distance traveled in the open field (Figure 2b). Our findings are supported by studies showing that exposure to nicotine and other psychostimulants results in depression-like states (Barr et al, 2002; Bolaños et al, 2003; Carlezon et al, 2003; Mannucci et al, 2006; Picciotto et al, 2002). Moreover, we show that these nicotine-induced behavioral deficits in the FST can be rescued by subsequent chronic exposure to the antidepressants FLX and BPN, or acute nicotine. These observations are in agreement with basic and clinical studies showing that nicotine has antidepressant properties (Salin-Pascual et al, 1996; Suemaru et al, 2006; Tizabi et al, 1999; VazquezPalacios et al, 2004), the well-known effects of antidepressant treatment in the FST (Cryan et al, 2002), and with studies suggesting that antidepressants can be effective in ameliorating dysphoric states followed by nicotine withdrawal/smoking cessation (Cryan et al, 2003; Hatsukami et al, 2008; Schnoll and Lerman, 2006). The cellular mechanism(s) underlying these effects are unknown. Nicotine, as well as FLX and BPN, interacts in a complex manner with serotonergic and dopaminergic systems by increasing neural activity and regulating neurotransmitter content to influence behavioral responding (Seth et al, 2002; Suemaru et al, 2006). Given that depression is associated with impaired functioning of these systems (Krishnan and Nestler, 2008b; Manji et al, 2001; Nestler and Carlezon, 2006), it is conceivable that these drugs enhance serotonin and dopamine transmission in mesolimbic brain regions to reverse depression-like behaviors induced by adolescent nicotine exposure.

Interestingly, nicotine did not influence behavioral responsivity of adolescent rats tested $24 \mathrm{~h}$ after cessation in any of the tests. Because signs of withdrawal can be observed up to $48 \mathrm{~h}$ following nicotine cessation in adult rodents (Kenny and Markou, 2001), we tested a separate group of adolescents in the FST 1 week after nicotine, and observed that these rats had shorter latencies to immobility and a lesser frequency of escape-like behaviors. These findings indicate that adolescent rats may not show the 'usual' trajectory of nicotine withdrawal as it is observed in adults (Wilmouth and Spear, 2006), or may reflect an agedependent subsensitivity to the drug (Bolaños et al, 1998; Spear and Brake, 1983). We did not determine nicotine metabolism between the age groups in this study and thus it is also possible that our drug regimen and dose did not induce 'dependence' in adolescent rats, as studies assessing dysphoric aspects of nicotine withdrawal use higher doses than the one used here (Matta et al, 2007), and also because our treatment did not affect the adult rats. Nevertheless, our findings are in agreement with the notion that the full spectrum of effects after drug exposure during development may not appear until later in life (ie 'drug effects incubate'; Andersen and Navalta, 2004), and with recent epidemiological findings indicating that novice adolescent smokers show significantly longer latencies (ie weeks) to the onset of withdrawal from nicotine as compared to experienced smokers (Difranza and Ursprung, 2008; Fernando et al, 2006). Here we further show that a single day of nicotine exposure during adolescence can be sufficient to induce depression-like behaviors in adulthood. This finding may not be too surprising because occasional/limited nicotine use can be sufficient to induce dependence in adolescents (DiFranza, 2008; DiFranza et al, 2000), and because longlasting synaptic changes can occur even after brief exposure to nicotine in young rats (Mansvelder and McGehee, 2000).

Together, our findings are in agreement with those showing that early-life exposure to psychostimulants has long-lasting effects: decreasing responsiveness to rewards, while enhancing sensitivity to aversive stimuli (Bolaños et al, 2003; Carlezon et al, 2003; Franke et al, 2008; Slawecki et al, 2003; Wiley et al, 2008). The mechanism(s) underlying nicotine's effects remain to be fully elucidated. Nicotine exposure has neurotoxic effects in several brain regions and neurotransmitter systems at distinct periods of development (Abreu-Villaca et al, 2003; Dwyer et al, 2008; Trauth et al, 2001). In addition, nicotine exposure regulates $\Delta$ FosB, CREB and ERK activity (Brunzell et al, 2003; Pluzarev and Pandey, 2004; Walters et al, 2005), factors associated with the regulation of mood and motivation (Bolaños and Nestler, 2004; Carlezon et al, 2005; Einat et al, 2003; Krishnan et al, 2008a; Wallace et al, 2008). Nicotine's actions on the nervous system are complex, and much more 
detailed assessments of these phenomena, accounting for length of exposure, discontinuation, and developmental periods, are clearly needed (Adriani and Laviola, 2004; Barron et al, 2005; Carlezon and Konradi, 2004).

Despite the lack of appropriate animal models to mirror the human condition (Fisch, 2007; Nestler et al, 2002), our findings may have clinical implications. Nicotine can alleviate negative affect, and because depression, increased stress, and anxiety often emerge during adolescence (Andersen and Teicher, 2008; Spear, 2000), afflicted individuals may initiate smoking to regulate mood through a self-medication process (Breslau et al, 2004b; Markou et al, 1998). Consequently, adolescence represents a period of increased vulnerability because early life tobacco use is associated with higher risks for psychiatric disorders later in life, and early psychiatric-related problems are linked to greater tobacco use and dependence (Patton et al, 2006; Upadhyaya et al, 2003; Volkow, 2004). Thus, our findings that nicotine exposure during adolescence leads to dysregulated mood in rats parallel reports suggesting that cigarette smoking during adolescence leads to the onset of depression and other psychiatric disorders (Breslau et al, 2004a; Choi et al, 1997; Goodman and Capitman, 2000; Steuber and Danner, 2006; Windle and Windle, 2001; Wu and Anthony, 1999). It is thus conceivable that some adolescents may initiate smoking as a way of selfmedicating preexisting mood disorder conditions (Alvarado and Breslau, 2005; Breslau et al, 2004b; Windle and Windle, 2001), whereas others would continue to smoke to manage mood dysregulation induced by their recreational exposure to nicotine itself (DiFranza et al, 2004; Parrott, 1999).

To summarize, our study shows that nicotine exposure during adolescence induces a negative emotional state characterized by anhedonia and heightened sensitivity to the adverse effects of stress later in life, that subsequent nicotine or antidepressant treatment normalize these depression-like behaviors, and that a relatively brief exposure to the drug can have long-lasting negative consequences (DiFranza, 2008; Mansvelder and McGehee, 2000). Within this context, our findings, together with those indicating that nicotine exposure during adolescence enhances risk for addiction (Adriani et al, 2003, 2006; McQuown et al, 2007), could serve as a potential model of comorbidity. Moreover, our findings underscore the need for further assessment of long-term neurobiological adaptations induced by early life experiences contributing to the pathophysiology of neuropsychiatric disorders later in life.

\section{ACKNOWLEDGEMENTS}

This work was supported by The James and Esther King Biomedical Program grant no. 07KN-01 from the Department of Health, State of Florida, a CRC Planning grant from Florida State University, and grants no. R03DA020089 and R21DA022351 from the National Institute on Drug Abuse to CABG. SD Iñiguez was supported by a McKnight Fellowship from the Florida Education Fund and a Neuroscience Fellowship from Florida State University. BL Warren was supported by a Neuroscience Fellowship from Florida State University.

\section{DISCLOSURE/CONFLICT OF INTEREST}

The authors have no financial or competing interests to declare.

\section{REFERENCES}

Abreu-Villaca Y, Seidler FJ, Tate CA, Slotkin TA (2003). Nicotine is a neurotoxin in the adolescent brain: critical periods, patterns of exposure, regional selectivity, and dose thresholds for macromolecular alterations. Brain Res 979: 114-128.

Adriani W, Deroche-Gamonet V, Le Moal M, Laviola G, Piazza PV (2006). Preexposure during or following adolescence differently affects nicotine-rewarding properties in adult rats. Psychopharmacology (Berl) 184: 382-390.

Adriani W, Laviola G (2004). Windows of vulnerability to psychopathology and therapeutic strategy in the adolescent rodent model. Behav Pharmacol 15: 341-352.

Adriani W, Spijker S, Deroche-Gamonet V, Laviola G, Le Moal M, Smit $\mathrm{AB}$ et al (2003). Evidence for enhanced neurobehavioral vulnerability to nicotine during periadolescence in rats. J Neurosci 23: 4712-4716.

Alvarado GF, Breslau N (2005). Smoking and young people's mental health. Curr Opin Psychiatry 18: 397-400.

Andersen SL, Navalta CP (2004). Altering the course of neurodevelopment: a framework for understanding the enduring effects of psychotropic drugs. Int J Dev Neurosci 22: 423-440.

Andersen SL, Teicher MH (2008). Stress, sensitive periods and maturational events in adolescent depression. Trends Neurosci 31: 183-191.

Barr AM, Markou A, Phillips AG (2002). A 'crash' course on psychostimulant withdrawal as a model of depression. Trends Pharmacol Sci 23: 475-482.

Barron S, White A, Swartzwelder HS, Bell RL, Rodd ZA, Slawecki CJ et al (2005). Adolescent vulnerabilities to chronic alcohol or nicotine exposure: findings from rodent models. Alcohol Clin Exp Res 29: 1720-1725.

Benowitz NL (1999). Nicotine addiction. Prim Care 26: 611-631.

Benowitz NL (2008). Clinical pharmacology of nicotine: implications for understanding, preventing, and treating tobacco addiction. Clin Pharmacol Ther 83: 531-541.

Bolaños CA, Barrot M, Berton O, Wallace-Black D, Nestler EJ (2003). Methylphenidate treatment during pre- and periadolescence alters behavioral responses to emotional stimuli at adulthood. Biol Psychiatry 54: 1317-1329.

Bolaños CA, Glatt SJ, Jackson D (1998). Subsensitivity to dopaminergic drugs in periadolescent rats: a behavioral and neurochemical analysis. Brain Res Dev Brain Res 111: 25-33.

Bolaños CA, Nestler EJ (2004). Neurotrophic mechanisms in drug addiction. Neuromolecular Med 5: 69-83.

Bolaños CA, Willey MD, Maffeo ML, Powers KD, Kinka DW, Grausam KB et al (2008). Antidepressant treatment can normalize adult behavioral deficits induced by early-life exposure to methylphenidate. Biol Psychiatry 63: 309-316.

Breslau N, Novak SP, Kessler RC (2004a). Daily smoking and the subsequent onset of psychiatric disorders. Psychol Med 34: 323-333.

Breslau N, Novak SP, Kessler RC (2004b). Psychiatric disorders and stages of smoking. Biol Psychiatry 55: 69-76.

Breslau N, Peterson EL, Schultz LR, Chilcoat HD, Andreski P (1998). Major depression and stages of smoking. A longitudinal investigation. Arch Gen Psychiatry 55: 161-166.

Britton DR, Britton KT (1981). A sensitive open field measure of anxiolytic drug activity. Pharmacol Biochem Behav 15: 577-582.

Brunzell DH, Russell DS, Picciotto MR (2003). In vivo nicotine treatment regulates mesocorticolimbic CREB and ERK signaling in C57Bl/6J mice. J Neurochem 84: 1431-1441. 
Carlezon Jr WA, Duman RS, Nestler EJ (2005). The many faces of CREB. Trends Neurosci 28: 436-445.

Carlezon Jr WA, Konradi C (2004). Understanding the neurobiological consequences of early exposure to psychotropic drugs: linking behavior with molecules. Neuropharmacology 47(Suppl 1): 47-60.

Carlezon Jr WA, Mague SD, Andersen SL (2003). Enduring behavioral effects of early exposure to methylphenidate in rats. Biol Psychiatry 54: 1330-1337.

Chao J, Nestler EJ (2004). Molecular neurobiology of drug addiction. Annu Rev Med 55: 113-132.

Choi WS, Patten CA, Gillin JC, Kaplan RM, Pierce JP (1997). Cigarette smoking predicts development of depressive symptoms among U.S. adolescents. Ann Behav Med 19: 42-50.

Clark DB, Kirisci L, Tarter RE (1998). Adolescent versus adult onset and the development of substance use disorders in males. Drug Alcohol Depend 49: 115-121.

Collins SL, Wade D, Ledon J, Izenwasser S (2004). Neurochemical alterations produced by daily nicotine exposure in periadolescent $v s$ adult male rats. Eur J Pharmacol 502: 75-85.

Connolly GN, Alpert HR (2008). Trends in the use of cigarettes and other tobacco products, 2000-2007. JAMA 299: 2629-2630.

Corrigall WA, Franklin KB, Coen KM, Clarke PB (1992). The mesolimbic dopaminergic system is implicated in the reinforcing effects of nicotine. Psychopharmacology (Berl) 107: 285-289.

Cryan JF, Bruijnzeel AW, Skjei KL, Markou A (2003). Bupropion enhances brain reward function and reverses the affective and somatic aspects of nicotine withdrawal in the rat. Psychopharmacology (Berl) 168: 347-358.

Cryan JF, Markou A, Lucki I (2002). Assessing antidepressant activity in rodents: recent developments and future needs. Trends Pharmacol Sci 23: 238-245.

Dani JA, Harris RA (2005). Nicotine addiction and comorbidity with alcohol abuse and mental illness. Nat Neurosci 8: $1465-1470$

Delnevo CD, Foulds J, Hrywna M (2005). Trading tobacco: are youths choosing cigars over cigarettes? Am J Public Health 95: 2123.

Detke MJ, Rickels M, Lucki I (1995). Active behaviors in the rat forced swimming test differentially produced by serotonergic and noradrenergic antidepressants. Psychopharmacology (Berl) 121: $66-72$.

DiFranza JR (2008). Hooked from the first cigarette. Sci Am 298: 82-87.

DiFranza JR, Rigotti NA, McNeill AD, Ockene JK, Savageau JA, St Cyr D et al (2000). Initial symptoms of nicotine dependence in adolescents. Tob Control 9: 313-319.

DiFranza JR, Savageau JA, Fletcher K, Ockene JK, Rigotti NA, McNeill AD et al (2004). Recollections and repercussions of the first inhaled cigarette. Addict Behav 29: 261-272.

Difranza JR, Ursprung WW (2008). The latency to the onset of nicotine withdrawal: a test of the sensitization-homeostasis theory. Addict Behav 33: 1148-1153.

Dornelas EA, Thompson PD (2007). Smoking cessation for cardiac patients. Prev Cardiol 10(2 Suppl 1): 31-33.

Dwyer JB, Broide RS, Leslie FM (2008). Nicotine and brain development. Birth Defects Res C Embryo Today 84: $30-44$.

Einat H, Yuan P, Gould TD, Li J, Du J, Zhang L et al (2003). The role of the extracellular signal-regulated kinase signaling pathway in mood modulation. J Neurosci 23: 7311-7316.

Ezzati M, Lopez AD (2003). Estimates of global mortality attributable to smoking in 2000. Lancet 362: 847-852.

Fernando WW, Wellman RJ, Difranza JR (2006). The relationship between level of cigarette consumption and latency to the onset of retrospectively reported withdrawal symptoms. Psychopharmacology (Berl) 188: 335-342.
Fisch GS (2007). Animal models and human neuropsychiatric disorders. Behav Genet 37: 1-10.

Franke RM, Park M, Belluzzi JD, Leslie FM (2008). Prenatal nicotine exposure changes natural and drug-induced reinforcement in adolescent male rats. Eur J Neurosci 27: 2952-2961.

Goodman E, Capitman J (2000). Depressive symptoms and cigarette smoking among teens. Pediatrics 106: 748-755.

Grant BF, Hasin DS, Chou SP, Stinson FS, Dawson DA (2004). Nicotine dependence and psychiatric disorders in the United States: results from the National Epidemiologic Survey on Alcohol and Related Conditions. Arch Gen Psychiatry 61: 1107-1115.

Greydanus DE, Patel DR (2005). The adolescent and substance abuse: current concepts. Curr Probl Pediatr Adolesc Health Care 35: 78-98.

Hajnal A, Norgren R (2001). Accumbens dopamine mechanisms in sucrose intake. Brain Res 904: 76-84.

Hatsukami DK, Stead LF, Gupta PC (2008). Tobacco addiction. Lancet 371: 2027-2038.

Huang LZ, Liu X, Griffith WH, Winzer-Serhan UH (2007). Chronic neonatal nicotine increases anxiety but does not impair cognition in adult rats. Behav Neurosci 121: 1342-1352.

John U, Meyer C, Rumpf HJ, Hapke U (2004). Depressive disorders are related to nicotine dependence in the population but do not necessarily hamper smoking cessation. J Clin Psychiatry 65: 169-176.

Johnston LD, O'Malley PM, Bachman JG, Schulenberg JE (2006). Decline in daily smoking by younger teens has ended. Ann Arbor, MI: University of Michigan News and Information Services Available on line at: http://wwwwmonitotingthefuture.org.

Kandel D, Chen K, Warner LA, Kessler RC, Grant B (1997). Prevalence and demographic correlates of symptoms of last year dependence on alcohol, nicotine, marijuana and cocaine in the U.S. population. Drug Alcohol Depend 44: 11-29.

Kelley AE, Berridge KC (2002). The neuroscience of natural rewards: relevance to addictive drugs. J Neurosci 22: 3306-3311.

Kenny PJ, Markou A (2001). Neurobiology of the nicotine withdrawal syndrome. Pharmacol Biochem Behav 70: 531-549.

Klungsoyr O, Nygard JF, Sorensen T, Sandanger I (2006). Cigarette smoking and incidence of first depressive episode: an 11-year, population-based follow-up study. Am J Epidemiol 163 421-432.

Koob GF, Le Moal M (2008). Addiction and the brain antireward system. Annu Rev Psychol 59: 29-53.

Krishnan V, Han MH, Mazei-Robison M, Iniguez SD, Ables JL, Vialou V et al (2008a). AKT signaling within the ventral tegmental area regulates cellular and behavioral responses to stressful stimuli. Biol Psychiatry 64: 691-700.

Krishnan V, Nestler EJ (2008b). The molecular neurobiology of depression. Nature 455: 894-902.

Laviolette SR, van der Kooy D (2004). The neurobiology of nicotine addiction: bridging the gap from molecules to behaviour. Nat Rev Neurosci 5: 55-65.

Lenney W, Enderby B (2008). 'Blowing in the wind': a review of teenage smoking. Arch Dis Child 93: 72-75.

Leonard S, Adler LE, Benhammou K, Berger R, Breese CR, Drebing $\mathrm{C}$ et al (2001). Smoking and mental illness. Pharmacol Biochem Behav 70: 561-570.

Lucki I (1997). The forced swimming test as a model for core and component behavioral effects of antidepressant drugs. Behav Pharmacol 8: 523-532.

Mague SD, Andersen SL, Carlezon Jr WA (2005). Early developmental exposure to methylphenidate reduces cocaine-induced potentiation of brain stimulation reward in rats. Biol Psychiatry 57: $120-125$.

Manji HK, Drevets WC, Charney DS (2001). The cellular neurobiology of depression. Nat Med 7: 541-547. 
Mannucci C, Tedesco M, Bellomo M, Caputi AP, Calapai G (2006). Long-term effects of nicotine on the forced swimming test in mice: an experimental model for the study of depression caused by smoke. Neurochem Int 49: 481-486.

Mansvelder HD, McGehee DS (2000). Long-term potentiation of excitatory inputs to brain reward areas by nicotine. Neuron 27: 349-357.

Markou A, Kosten TR, Koob GF (1998). Neurobiological similarities in depression and drug dependence: a self-medication hypothesis. Neuropsychopharmacology 18: 135-174.

Matta SG, Balfour DJ, Benowitz NL, Boyd RT, Buccafusco JJ, Caggiula AR et al (2007). Guidelines on nicotine dose selection for in vivo research. Psychopharmacology (Berl) 190: 269-319.

McQuown SC, Belluzzi JD, Leslie FM (2007). Low dose nicotine treatment during early adolescence increases subsequent cocaine reward. Neurotoxicol Teratol 29: 66-73.

Nestler EJ, Carlezon Jr WA (2006). The mesolimbic dopamine reward circuit in depression. Biol Psychiatry 59: 1151-1159.

Nestler EJ, Gould E, Manji H, Buncan M, Duman RS, Greshenfeld HK et al (2002). Preclinical models: status of basic research in depression. Biol Psychiatry 52: 503-528.

O'Loughlin J, Kishchuk N, DiFranza J, Tremblay M, Paradis G (2002). The hardest thing is the habit: a qualitative investigation of adolescent smokers' experience of nicotine dependence. Nicotine Tob Res 4: 201-209.

Papp M, Willner P, Muscat R (1991). An animal model of anhedonia: attenuation of sucrose consumption and place preference conditioning by chronic unpredictable mild stress. Psychopharmacology (Berl) 104: 255-259.

Parrott AC (1999). Does cigarette smoking cause stress? Am Psychol 54: 817-820.

Patton GC, Coffey C, Carlin JB, Sawyer SM, Wakefield M (2006). Teen smokers reach their mid twenties. J Adolesc Health 39: $214-220$.

Picciotto MR (2003). Nicotine as a modulator of behavior: beyond the inverted U. Trends Pharmacol Sci 24: 493-499.

Picciotto MR, Brunzell DH, Caldarone BJ (2002). Effect of nicotine and nicotinic receptors on anxiety and depression. Neuroreport 13: 1097-1106.

Pluzarev O, Pandey SC (2004). Modulation of CREB expression and phosphorylation in the rat nucleus accumbens during nicotine exposure and withdrawal. $J$ Neurosci Res 77: 884-891.

Porsolt RD, Le Pichon M, Jalfre M (1977). Depression: a new animal model sensitive to antidepressant treatments. Nature 266: 730-732.

Salin-Pascual RJ, Rosas M, Jimenez-Genchi A, Rivera-Meza BL, Delgado-Parra V (1996). Antidepressant effect of transdermal nicotine patches in nonsmoking patients with major depression. J Clin Psychiatry 57: 387-389.

Sampson D, Muscat R, Phillips G, Willner P (1992). Decreased reactivity to sweetness following chronic exposure to mild unpredictable stress or acute administration of pimozide. Neurosci Biobehav Rev 16: 519-524.

Schnoll RA, Lerman C (2006). Current and emerging pharmacotherapies for treating tobacco dependence. Expert Opin Emerg Drugs 11: 429-444.

Seth P, Cheeta S, Tucci S, File SE (2002). Nicotinic-serotonergic interactions in brain and behaviour. Pharmacol Biochem Behav 71: 795-805.

Shimura T, Kamada Y, Yamamoto T (2002). Ventral tegmental lesions reduce overconsumption of normally preferred taste fluid in rats. Behav Brain Res 134: 123-130.

Slawecki CJ, Ehlers CL (2002). Lasting effects of adolescent nicotine exposure on the electroencephalogram, event related potentials, and locomotor activity in the rat. Brain Res Dev Brain Res 138: 15-25.
Slawecki CJ, Gilder A, Roth J, Ehlers CL (2003). Increased anxietylike behavior in adult rats exposed to nicotine as adolescents. Pharmacol Biochem Behav 75: 355-361.

Slawecki CJ, Thorsell AK, El Khoury A, Mathe AA, Ehlers CL (2005). Increased CRF-like and NPY-like immunoreactivity in adult rats exposed to nicotine during adolescence: relation to anxiety-like and depressive-like behavior. Neuropeptides 39: 369-377.

Spear LP (2000). The adolescent brain and age-related behavioral manifestations. Neurosci Biobehav Rev 24: 417-463.

Spear LP, Brake SC (1983). Periadolescence: age-dependent behavior and psychopharmacological responsivity in rats. Dev Psychobiol 16: 83-109.

Spruijt BM, Welbergen P, Brakkee J, Gispen WH (1988). An ethological analysis of excessive grooming in young and aged rats. Ann NY Acad Sci 525: 89-100.

Steuber TL, Danner F (2006). Adolescent smoking and depression: which comes first? Addict Behav 31: 133-136.

Suemaru K, Yasuda K, Cui R, Li B, Umeda K, Amano M et al (2006). Antidepressant-like action of nicotine in forced swimming test and brain serotonin in mice. Physiol Behav 88: 545-549.

Thompson F, Fagerstrom K (2006). Current trends in international tobacco control. Clin Occup Environ Med 5: 101116, ix.

Thorndike AN, Regan S, McKool K, Pasternak RC, Swartz S, Torres-Finnerty $\mathrm{N}$ et al (2008). Depressive symptoms and smoking cessation after hospitalization for cardiovascular disease. Arch Intern Med 168: 186-191.

Tizabi Y, Overstreet DH, Rezvani AH, Louis VA, Clark Jr E, Janowsky DS et al (1999). Antidepressant effects of nicotine in an animal model of depression. Psychopharmacology (Berl) 142: 193-199.

Trauth JA, Seidler FJ, Ali SF, Slotkin TA (2001). Adolescent nicotine exposure produces immediate and long-term changes in CNS noradrenergic and dopaminergic function. Brain Res 892: 269-280.

Upadhyaya HP, Brady KT, Wharton M, Liao J (2003). Psychiatric disorders and cigarette smoking among child and adolescent psychiatry inpatients. Am $J$ Addict 12: 144-152.

Vastola BJ, Douglas LA, Varlinskaya EI, Spear LP (2002). Nicotineinduced conditioned place preference in adolescent and adult rats. Physiol Behav 77: 107-114.

Vazquez-Palacios G, Bonilla-Jaime H, Velazquez-Moctezuma J (2004). Antidepressant-like effects of the acute and chronic administration of nicotine in the rat forced swimming test and its interaction with fluoxetine (correction of flouxetine). Pharmacol Biochem Behav 78: 165-169.

Volkow ND (2004). The reality of comorbidity: depression and drug abuse. Biol Psychiatry 56: 714-717.

Wallace DL, Vialou V, Rios L, Carle-Florence TL, Chakravarty S, Kumar A et al (2008). The influence of DeltaFosB in the nucleus accumbens on natural reward-related behavior. J Neurosci 28: 10272-10277.

Walters CL, Cleck JN, Kuo YC, Blendy JA (2005). Mu-opioid receptor and CREB activation are required for nicotine reward. Neuron 46: 933-943.

Warren CW, Jones NR, Peruga A, Chauvin J, Baptiste JP, Costa de Silva V et al (2008). Global youth tobacco surveillance, 20002007. MMWR Surveill Summ 57: 1-28.

Wiley MD, Poveromo LB, Antapasis J, Herrera CM, Bolanos Guzman CA (2008). kappa-Opioid system regulates the longlasting behavioral adaptations induced by early-life exposure to methylphenidate. Neuropsychopharmacology.

Wilkinson JL, Bevins RA (2007). Bupropion hydrochloride produces conditioned hyperactivity in rats. Physiol Behav 90: 790-796. 
Wilkinson JL, Palmatier MI, Bevins RA (2006). Preexposure to nicotine alters the subsequent locomotor stimulant effects of bupropion in rats. Nicotine Tob Res 8: 141-146.

Wilmouth CE, Spear LP (2006). Withdrawal from chronic nicotine in adolescent and adult rats. Pharmacol Biochem Behav 85: 648-657.

Windle M, Windle RC (2001). Depressive symptoms and cigarette smoking among middle adolescents: prospective associations and intrapersonal and interpersonal influences. J Consult Clin Psychol 69: 215-226.
Wu LT, Anthony JC (1999). Tobacco smoking and depressed mood in late childhood and early adolescence. Am J Public Health 89: $1837-1840$

Zachariou V, Caldarone BJ, Weathers-Lowin A, George TP, Elsworth JD, Roth RH et al (2001). Nicotine receptor inactivation decreases sensitivity to cocaine. Neuropsychopharmacology 24: 576-589.

Zubaran C, Shoaib M, Stolerman IP (2000). The development and expression of locomotor sensitization to nicotine in the presence of ibogaine. Behav Pharmacol 11: 431-436. 